\title{
Neutral Liposomes and DNA Transfection
}

\author{
Michela Pisani, Giovanna Mobbili and Paolo Bruni \\ Marche Polytechnic University \\ Italy
}

\section{Introduction}

Non viral gene transfer vectors for human gene therapy (HGT) applications represent today one of the widest fields of chemical, biological and medical research. Some authors (Kostaleros \& Miller, 2005) have expressed the opinion that the future of a safe and efficient gene therapy will depend on suitable synthetic vectors of genetic material, rather than on viruses. The reason for this preference is based on the consideration that viruses, although characterized by high transfection efficiency of genetic material, may suffer from some serious disadvantages such as immune response (Marshall, 2000) and potential oncogenic activity (Hacein-Bey-Abina et al., 2003), as well as a high cost of preparation of the transferring system. On the contrary, synthetic vectors have many potential advantages, such as lack of immunogenicity and oncogenicity, no limits to the size of nucleic acids to be carried inside the cells (Harrington et al., 1997; Roush, 1997; Willard, 2000) and finally preparation procedures cheap and easy to perform. Nevertheless an awkward problem that accompanies their use is the low efficiency of the transfections in vivo. Among the synthetic vectors, the most explored by the researchers are the cationic liposomes (CLs), after Felgner and collaborators (Felgner et al., 1997) described the synthesis of the first cation lipid, N-[1(2,3-dioleoyloxy)propyl]-N,N,N-trimethylammonium chloride (DOTMA) and demonstrated that it was able to bind DNA and transfect it both in vitro and in vivo experiments. Other cationic lipids followed and became popular, such as the commercially widely used N-[1(2,3-dioleoyloxy)propyl]-N,N,N-trimethylammonium methylsulfate (DOTAP), 1,2-dioleoyl3-dimethylammonium-propane (DODAP), dimethyldioctadecylammonium bromide

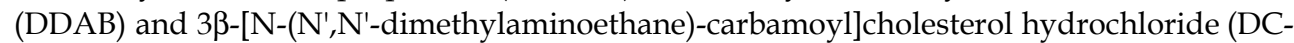
Chol); many others were synthesized during the past years and are still being synthesized. A few years after the Felgner's discovery scientists' interest was focused also on cationic polymers (Wu, G.Y. \& Wu; C.H., 1987), that became popular after the discovery of polyethylenimines (Boussif, 1995) and are still the object of great interest. Both classes of cationic compounds owe their interest to the formation of stable complexes with DNA, called lipoplexes and polyplexes respectively, formed through an electrostatic interaction between the cationic head of lipids and the negative phosphates of DNA. The great amount of data and experiments reported in the literature with cationic vectors and some encouraging results in in vivo transfection experiments have led to the significant milestone of $20 \%$ of the ongoing clinical trials run with synthetic vectors (Edelstein et al., 2004): however the goal of a higher efficiency is still a problem to be solved. As recently stated (Safinya et al., 2006), the long-term target of research in this area is to develop a general 
fundamental theory, that may help to design and implement the synthesis of specialized vectors able to offer the highest efficiency in the various in vivo applications. Accordingly, the prevailing opinion is that more exhaustive research and development will be required before such efficiency becomes competitive with viral vectors. As a matter of fact the experience shows that also the cationic carriers suffer from some serious drawbacks, affecting more or less negatively their efficiency of transfection: namely some inherent cytotoxicity (Filion \& Phillips, 1998; Lv et al., 2006) that causes negative effects on cells, such as shrinking and inhibition of the protein kinase $\mathrm{C}$ (PKC) and a limited stability of their complexes with plasmid DNA in serum (Foradada et al., 2000), responsible for the current restriction of a generalized and extensive use. In this situation the idea of using neutral liposomes as carriers of DNA seems to be interesting and can offer good prospects. It is well known that neutral liposomes are generally non toxic (Koiv et al., 1995) and relatively stable in serum (Tardi et al., 1996), which makes them potentially interesting gene transfer vectors. Despite these strategic features, neutral liposomes (NLs) have not yet received wide attention in the context of the HGT, even though the researchers' initial interest for DNA entrapment was turned to neutral liposomes (Budker et al., 1978). Likely, there are two causes for this situation: the first, and more important, is the lack of positive charge that makes virtually impossible to realize an interaction stable enough between NLs and DNA; the second is the great leading role assumed by the cationic carriers, which have polarized the researchers' interest, leaving other alternatives aside.

In this chapter we will deal with NLs following two separate paths, according to different functions they exert in HGT applications. The former will deal with their role of helpers of DNA transfection when used in mixture with cationic liposomes; the latter with their achievements and perspectives as autonomous and independent carriers of DNA. A survey of the literature published so far, though not too extensive, enables to foresee interesting prospects for NLs as promising synthetic vectors of genetic material. Perhaps they will be considered in a near future as an alternative to cationic vectors, rather than a provocative challenge. This forecast is supported by the results of several studies: of course deeper investigation is necessary in order to define a frame appropriate to treat correctly the many aspects of the transfection process and find better experimental conditions to warrant high transfection efficiency, particularly in vivo. The large number of studies carried on so far and the very large number of data collected in the field of cationic liposomes will help in building this frame and exploring the different aspects of the specific transfection with NLs.

\section{Neutral lipids as helpers of cationic liposomes in DNA transfection}

Since the discovery of the cationic liposomes as DNA carriers for gene transfer applications it has been clear that higher efficiencies could be obtained by adding a neutral lipid to the lipoplexes with the role of transfection helper. The approach followed in this section is not to evaluate all the issues related to DNA transfection with lipoplexes mediated by neutral lipids, but rather discuss the specific role of neutral lipids in determining the lipoplex transfection efficiency. The ultimate purpose is to highlight the factors that cause such increase of efficiency and check how they may help in designing the best experimental conditions for the transfections procedures with independent NLs.

Cationic systems for gene therapy are generally prepared by mixing a cationic lipid with DNA and a neutral helper co-lipid; such non toxic helper induces the dual result to reduce 
the amount of the toxic cationic component and, more important, to alter the physical properties of the delivery vehicle, in a way that favours some of the most complex steps of the whole mechanism of transfection: the consequence is that both actions affect the quality of the transfection. The most widely used neutral helpers in DNA transfection experiments are the 1,2-dioleoyl-sn-glycero-3-phosphocholine (DOPC) and the 1,2-dioleoyl-sn-glycero-3phosphoethanolamine (DOPE), sometimes in combination with cholesterol: the main difference between the two phospholipids is that DOPC induces a lamellar $\mathrm{L}_{\alpha}^{\mathrm{C}}$ phase in the lipoplexes, while DOPE induces an inverted hexagonal $\mathrm{H}_{\mathrm{II}}^{\mathrm{C}}$ phase. Earlier studies led to propose that DOPE is responsible for more efficient transfections because its hexagonal phase is able to fuse readily with anionic vesicles (Koltover et al., 1998) and destabilize the bilayer membranes, making easier the DNA escape from the endosomes, once the lipoplex has entered the cells. Therefore it was believed that DOPE was more useful than DOPC to realize the most efficient transfections. In support of this claim it was also suggested (Mui et al., 2000) that the inverted hexagonal phase promoted by DOPE has a higher ability to disrupt the membrane integrity than the lamellar one induced by DOPC. It turned soon evident that the situation was not so simple and the interpretation was not unambiguous: indeed, if it is verified that the DNA complex with cationic DOTAP, in which DOPE is present as helper in an amount of $70 \%$, transfects better than the corresponding complex including the same amount of DOPC (Koltover et al., 1998), lamellar $\mathrm{L}_{\alpha}^{\mathrm{C}}$ complexes, showing similar transfection efficiency, were also synthesized ( Lin et al., 2003). More generally, many literature data show the difficulty in finding a general correlation between vector formulations and transfection efficiency. Trying to explain these apparently contradictory results, some researchers have recently suggested the opportunity to consider the possibility that complexes can bear a structural modification within the phase of the interaction of the systems DNA-carrier with each individual cell, the transition $\mathrm{L}_{\alpha}^{\mathrm{C}}$ to $\mathrm{H}_{\mathrm{II}}^{\mathrm{C}}$ phase being an example among others (Safinya, 2001). Starting from the observation that a large number of efficient complexes are assembled in the $\mathrm{L}_{\alpha}^{\mathrm{C}}$ phase, it was suggested (Caracciolo \& Caminiti, 2005) that perhaps a compelling correlation between the structure of a complex and its transfection efficiency does not simply exist and that the lower transfection efficiency of the synthetic carriers of DNA with respect to virus depends on a poor understanding of the supramolecular structures of the complexes, on the mechanism of their interaction with cells and of the release of DNA within the nucleus. If these statements are true, and there are reasons to confirm them, a more exhaustive knowledge of the subject is particularly important also with reference to the use of NLs as independent carriers of DNA, because it is likely that similar problems will arise and the need to overcome them will be even more important. Of course, understanding the mechanism is crucial for any successful design of a non viral gene delivery, whatever path has been chosen. Besides some early studies, that assumed a fusion between liposomes and cell membranes as the initial step of the process, it is today recognized that the uptake into an endocytic pathway is required for fusion to occur (Wrobel \& Collins, 1995) and the whole aspect has been the object of deep attention (Liu \& Huang, 2002) leading to suggest some main steps, namely non specific interaction with the cell surface, endocytosis into endocytic vesicles, trafficking and release of the DNA from endosomal compartment, nuclear uptake and transgene expression.

Special attention was also devoted to the intracellular trafficking of cationic vectors and the role of neutral helpers (Elouahabi \& Ruysschaert, 2005): six steps of the whole transfection 
process were identified and analyzed, namely (i) interaction between vectors and nucleic acids with formation of complexes, (ii) binding of a complex to the cell, (iii) effect of serum, (iv) uptake of the complex by the cell, (v) escape from endosomes and dissociation of the complex and finally (vi) nuclear entry of DNA.

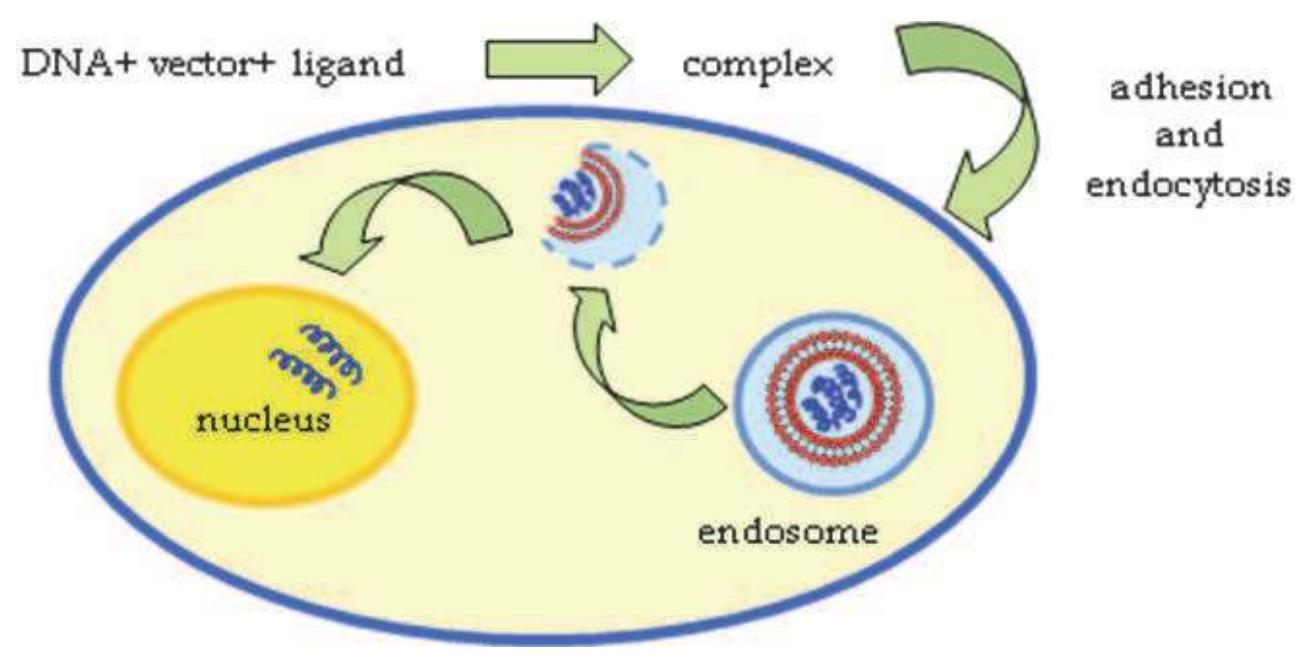

Fig. 1. A schematic representation of the steps involved in the liposome mediated DNA transfection.

We will consider here only the aspects likely to have significant involvements on the transfection process operated by NLs as unique carriers of genetic material. Neutral helpers play a not marginal role in the formation of the complexes: meaningful, though in some way contradictory, is the role of the helpers in determining the effect of serum on the uptake of lipoplexes, an issue that has implications in the in vivo transfections. No significant inhibition of serum was observed in transfecting COS-7 cells with cationic pyridiniumderived lipids (SAINT) in DOPE/DNA lipoplexes (Zuhorn et al., 2002), while a strong inhibitory effect operates in lipoplexes obtained by polycationic lipids like DOGS. However this negative effect may be avoided if one operates at slight alkaline $\mathrm{pH}$ that favours a lamellar organisation of the lipoplexes (Boukhnikachvili et al., 1997). Likewise DOTAP/DOPE and DC-Chol/DOPE prepared at high +/- charge ratio are not sensitive to the inhibitory effect of serum and indeed, at some ratios, are even more efficient (Yang \& Huang, 1997). A different perspective on the role of helpers is offered by other researchers: it was observed (Fasbender \& al., 1997) that when DOPE is incorporated into the complexes of DNA with three different cationics, its effect on the gene expression in COS-1 cells is different, depending on each cationic lipid. When the cationic lipids and DOPE were formulated separately and then complexed with DNA, no difference in activity was observed over that obtained with cationic lipids alone. Finally (Felgner et al., 1994) unsaturated PE co-lipids enhance lipoplexes activity while saturated PE and PC have no enhancing effect or even have an inhibitory effect. 


\section{CATIONIC LIPIDS}
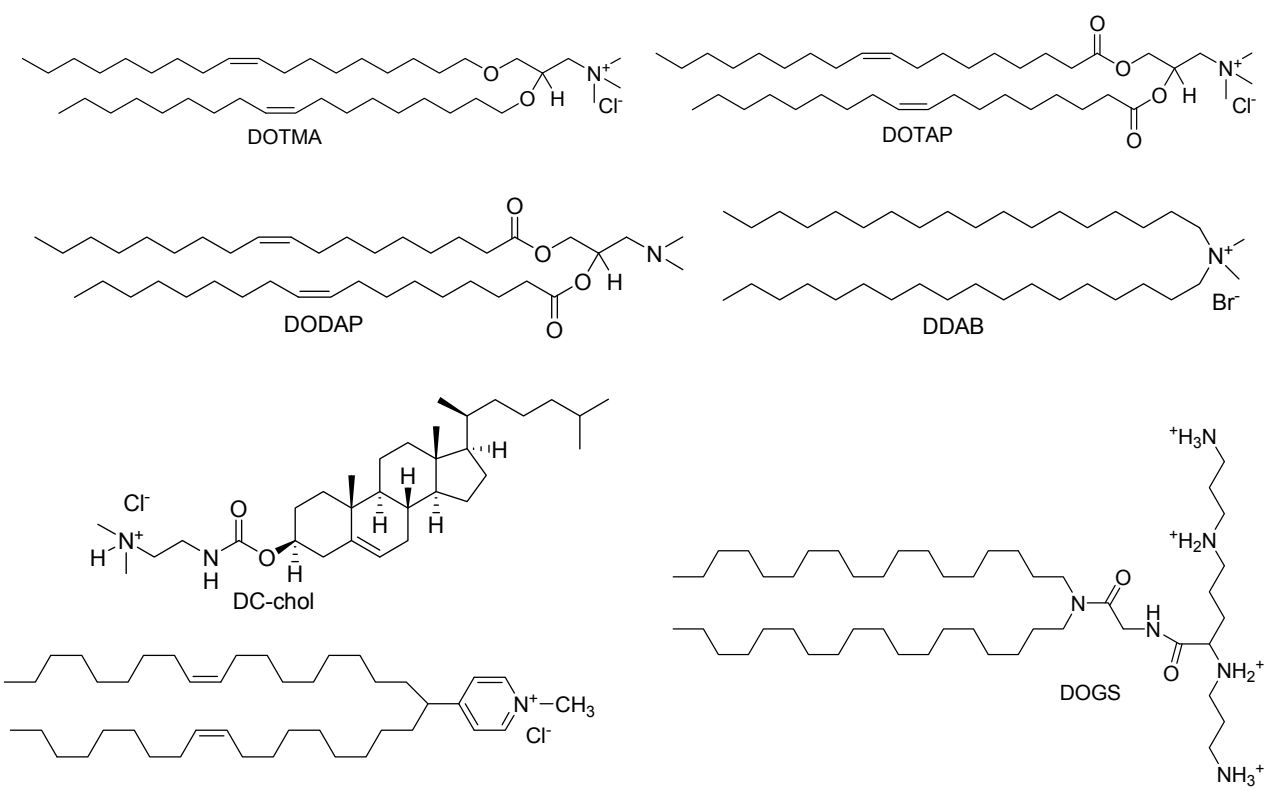

SAINT-2

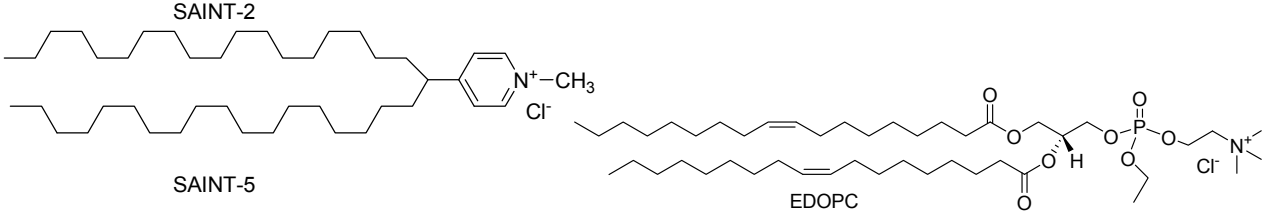

The escape of DNA from the endosomes is strictly depending on the nature of the neutral co-lipid: it was found that the fusion with endosomes is likely the way for the release of DNA into the cytoplasm. This mechanism was supported by the finding that efficient transfections require the fusogenic lipid DOPE, which is able to promote a transition from bilayers to hexagonal structures, the latter being known to catalyze the fusion process (Koltover et al., 1998; Mok \& Cullis, 1997). The ability of liposomes to fuse with endosomal membranes was also proved by several studies (Koltover et al., 1998; Farhood et al., 1995; Mok \& Cullis, 1997) and some evidence was found that the helper lipids can adapt their actions depending on the cationic lipid and the target cells (Fasbender et al., 1997).

In order to better clear up the situation, an interesting study was made a few years ago (Zuhorn et al., 2005). It provides deeper insight into the involvement of helper lipids in the liposomes mediated gene delivery. Two different helpers, DOPE, which has a propensity to adopt an inverted hexagonal phase, and the lamellar phase forming dipalmitoylphosphatidylethanolamine (DPPE), have been compared as neutral co-lipids in lipoplexes formed with SAINT-2 and plasmid DNA, with the specific aim of studying the endosomal escape of the genetic cargo in the cytosol for transport to the nucleus. As usual, it was found that the helper determines the in vitro transfection efficiency (COS-7 cells were used), DPPE inducing a significantly lower efficiency ( $\cong 25 \%$ of cell transfected) than DOPE 


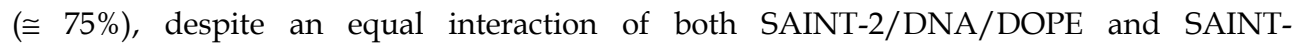
2/DNA/DPPE with cells. Assuming that the translocation of the nucleic acids through the endosomal membrane is the crucial step of the overall process, a mimic membrane consisting of phosphatidylserine (PS): phosphatidylcholine (PC): phosphatidylethanolamine (PE) anionic vesicle was used to simulate this step. Without helper lipids, a limited fraction of DNA was released from SAINT-2 lipoplex and no effect was promoted by the inclusion of DOPC. On the contrary, inclusion of DOPE significantly enhanced the amount of DNA released and, more interesting, a comparable effect was induced by DPPE (40\% release for DPPE versus $50 \%$ for DOPE). This result can find an explanation since the $x$-ray diffraction analysis after incubation of SAINT-2/DPPE with the anionic PS:PC:PE (1:1:2) revealed the presence of a mixed lamellar-hexagonal phase. The lower efficiency of the DPPE containing complex is consistent with this partial transition from the lamellar to the hexagonal phase. These results confirm that the limiting step in the overall transfection pathway depends on the level of DNA translocation through the endosomal membrane. The results obtained in the transfections with two different lipoplexes containing SAINT with different tails, namely SAINT-2 (C18:1) and SAINT-5 (C18:0) lead (Zuhorn et al., 2002) to analogous conclusions. Both amphiphiles may make transfection and DOPE strongly promotes the SAINT-2 mediated one, but not the SAINT-5. The relatively rigid SAINT-5 membrane forms structurally deformed lipoplexes hampering the plasmid translocation through endosomal and/or nuclear membranes.

What it has been said so far makes clear that there are still many aspects concerning the DNA transfection process that require a better investigation: among them, the need of a comprehensive knowledge of what really happens when a lipid-DNA complex interacts with a cell, an issue extremely important also in the neutral lipid mediated DNA transfections. In this connection a new perspective has gained recently ground: it identifies as one of the most critical factors of the transfection process the evolution of the structure of the lipoplexes that occurs when they interact with cells. That means to introduce the idea that the differences in the transfection efficiency, often observed and not always unambiguously interpreted, may depend on each particular cellular variety and emphasize the importance to consider both lipid composition of lipoplexes and target membranes (Koynova et al., 2005). Ancestors of this new perspective are some studies that demonstrated the ability of anionic lipids to promote the release of DNA from lipoplexes, by neutralizing their positive charge (Szoka et al. 1996; Zelphati \& Szoka, 1996; McDonald et al., 1999). It was observed that the DNA release from complexes with the cationic lipids o-ethyldioleoylphosphatidylcholinium (EDOPC) or DOTAP, after mixing them with some different negatively charged lipids, depends on both lipoplexes and negative lipids. Most significant, the transfection efficiencies of DNA complexes with two very similar cationic phospholipids, bearing only a minimal structural difference in one of the two hydrocarbon tails, the carbon-carbon double bond bearing oleoyldecanoyl-ethylphosphatidylcholine (C18:1/C10-EPC) and the completely saturated stearoyldecanoyl-ethylphosphatidylcholine (C18:0/C10-EPC) were compared (Koynova et al., 2006). The former complex shows a 50-fold higher transfection efficiency than the latter in human umbilical artery endothelial cells. A reasonable explanation of this different behaviour lies in the great difference of these lipids in the phase evolution found in mixing with biomembrane mimicking lipid mixtures (DOPC/DOPE/DOPS/chol). The $\mathrm{C} 18: 1$ lipoplex underwent a transition to the fusogenic non lamellar cubic phase, whereas 
the C18:0 did not. All these new perspectives must be seriously considered by all aiming at studying the DNA transfection with NLs, since an analogous behaviour will be probably characterize those experimental setups.

Before ending these considerations on the role of the helper co-lipids in the processes of non viral DNA transfection, it is advisable to say something about a neglected aspect of the topic. As a matter of fact it is surprising that the continuous growing of number and features of cationic lipids, in the search for most suitable vectors of genetic material, no analogous interest has been reserved, for many years, for new co-lipids. The idea that improved transfections could be realized also with the aid of new and more appropriate helpers has developed only in the last ten years. After the discovery that high transfection efficiency could be obtained with fluorinated double chain lipospermines, forming fluorinated lipoplexes (Gaucheron et al., 2001a, 2001b), a partially fluorinated analogue of DOPE, identified as [F8E11][C16]OPE from the number of fluorine atoms, was synthesized and compared with DOPE as helper of fluorinated lipoplexes (Boussif et al., 2001): this compound, inactive itself in promoting transfection, increased the in vitro and in vivo gene transfer of the lipoplex obtained from the pentacationic pcTG90 to a larger extent than DOPE. The synthesis was then extended to more fluorinated glycerophosphoethanolamines (Gaucheron et al., 2001) confirming that lipoplexes formulated with fluorinated helper lipids are attractive candidates for gene delivery both in vitro and in vivo. Several reasons were identified to explain these results: fluorinated colipids have a larger ability to preserve the integrity of complexed DNA in a biological environment and a larger propensity to promote fusion with endosomes and subsequent destabilisation, allowing more efficient DNA release in the cytosol; their high hydrophobic and lipophobic character can preserve the lipoplexes from the effect of the interactions with lipophilic and hydrophilic biocompounds; finally fluorinated DOPE compounds are expected to have a greater tendency to promote a lamellar to a an inverted hexagonal phase transition with the consequence of a higher effectiveness in disrupting membranes than DOPE.

It is commonly accepted that one of the main features of DOPE as helper depends on its polymorphism under various concentration and temperature conditions. Its ability to enhance transfection efficiency is related to its preference for the fusogenic $\mathrm{H}_{\text {II }}$ phase, which can promote fusion with cellular membranes, especially the endosomal ones, thereby facilitating the escape of the genetic material; however, the low $\mathrm{L}_{\alpha} / \mathrm{H}_{\text {II }}$ phase transition temperature $\left(\mathrm{T}_{\mathrm{h}}=10^{\circ} \mathrm{C}\right)$ makes cationic liposomes too unstable in the in vivo environment. An approach to solve the problem might be to synthesize analogues of DOPE in which the phase transition is near the physiological temperature. Some molecules having these characteristics have been synthesized (Fletcher et al., 2006) and correspond to a series of dialkynoyl analogues of DOPE where the cis-double bond in the two oleoyl fatty acid chains is replaced by a triple bond located in different positions of the hydrocarbon tails. With this modified geometry a new intermolecular packing is realized, able to induce an increase of the phase transition at the physiological conditions.

The achievements just shown were based on the concept to modify DOPE: a different approach to the search for more efficient helpers has been realized by synthesizing completely new lipids characterized by the presence of an imidazole polar head (Mével et al., 2008). These lipophosphoramides are neutral at physiological $\mathrm{pH}$ : the protonation occurring in the acidic compartments of the cell, namely the endosomes, induces fusion of 
liposomes with endosomes and structural changes that favour the release of DNA in the cytosol. Three phosphoramidates with a cationic polar head derived from natural aminoesters or a methylimidazolium salt were also synthesized and these cationic lipids were formulated with each one of the two new helpers and with cholesterol or DOPE for a comparison of transfections; it is worth noticing that the new helper lipids can improve the transfection by a factor of 100 compared with DOPE.

\section{Liposomes and membrane fusion mimicking}

A remote introduction to the processes of gene transfer is represented by a series of studies aiming at mimicking the process of cell fusion by using model membranes mainly composed of phosphatidylcholine (PC) and phosphatidylserine (PS). It was demonstrated that addition of liposomes containing these lipids fuse with plasma membranes in the presence of $\mathrm{Ca}^{2+}$ and $\mathrm{Mg}^{2+}$ (Papahadjopoulos et al., 1976). Considering that cellular fusion is one of the most fundamental processes in life and that its role has been recognized in the interaction of liposomes with endosomes within the processes of DNA transfection, such studies are highly significant for the knowledge of this particular step of the non viral GT and in designing lipids with the highest characteristics of fusion. The study of the effect of divalent metal cations in the interaction and mixing of membrane components in vesicles prepared from phospholipids led to find that low amounts of $\mathrm{Ca}^{2+}$ and $\mathrm{Mg}^{2+}$ induce extensive mixing of vesicle membrane components and important structural rearrangements to form new membrane structures. The result is a true fusion rather than a simple mixing of vesicles that occurs in the absence of cations. Some evidence was found that fusion of vesicle membranes by $\mathrm{Ca}^{2+}$ and $\mathrm{Mg}^{2+}$ is not simply due to electrostatic charge neutralization, but rather to changes in molecular packing. It is possible to see here an anticipation of the phase transitions that many years after was demonstrated to occur in DNA transfection with co-lipid added lipoplexes, as reported in the previous section. These results have been confirmed by finding that $\mathrm{Ca}^{2+}$ and $\mathrm{Mg}^{2+}$ produce structurally different complexes with PE (Newton et al., 1978). A different behaviour in fusion induced by these two cations was found in mixture of PS/PC, PS/PE and PS/PC/PE (Düzgünes et al. 1981). The extent of fusion by $\mathrm{Ca}^{2+}$ in mixed PE/PC was lower compared to that of pure PS vesicles and was completely inhibited when PC reached $50 \%$ in the mixture; rapid fusion was instead obtained in mixtures PS/PE. $\mathrm{Mg}^{2+}$ can fuse PS only in the presence of PE. The fusogenic capacity of $\mathrm{Mg}^{2+}$ was instead completely absent in mixtures PS/PC/PE with $10 \%$ of PC. These results show clearly a marked difference between $\mathrm{Ca}^{2+}$ and $\mathrm{Mg}^{2+}$ against fusion: as we will see later, this difference will appear also in some processes concerning the formation of complexes of DNA with neutral liposomes.

A rational mechanism to interpret these results was tried out: kinetics of the interaction between PS vesicles in the presence of $\mathrm{Ca}^{2+}$ (Portis et al., 1979) show the formation of two different complexes: the former develops when the cations bind only to individual vesicles, the latter, which seems correlated with the beginning of membrane fusion, when the vesicles come to close apposition; the former complex is obtained also with $\mathrm{Mg}^{2+}$. Its characteristics led to suggest that this complex is formed when the divalent cations bind to PS head groups on one bilayer only (cis complex). The latter, obtained only with $\mathrm{Ca}^{2+}$, shows different characteristics and seems to involve a polydentate chelation of $\mathrm{Ca}^{2+}$ with 
the head groups of PS from apposed membranes (trans complex). The formation of this $\mathrm{PS} / \mathrm{Ca}^{2+}$ complex is of crucial importance for the fusion of the vesicles. Apart from the names used to identify these complexes, it is worth noting that the structure suggested for the latter complex agrees with the one found in the complex between the neutral lipid DPPC and DNA, promoted by divalent metal cations, showing a $\mathrm{L}_{\alpha}^{\mathrm{C}}$ phase. A more detailed study (Wilschut et al., 1980) allowed to obtain further information about the process: it was demonstrated that fusion is one of the earliest events during the $\mathrm{Ca}^{2+}$ induced aggregation of SUVs (small unilamellar vesicles) of PS and occurs at a similar time scale, which means that fusion doesn't require initial rupture of the vesicles. The close contact between the vesicles induced by $\mathrm{Ca}^{2+}$ is sufficient to trigger the immediate fusion of the two membranes and the mixing of the internal volumes with a relative low leakiness of their content: which makes the $\mathrm{Ca}^{2+} / \mathrm{PS}$ system an almost ideal model for membrane fusion. This model has been later deeply developed and is the basis to explain the processes which occur in the cytosol when the complexes liposomes/DNA encounter the endosomes and release the DNA. With these last findings the route to the DNA delivery to cells by means of liposomes was opened.

\section{The neutral liposomes as independent DNA transfection agents}

After the Bangham's work (Bangham et al., 1965) liposomes were extensively used as models of biological membranes (Sessa \& Weissmann, 1968) on the basis of their lamellar structure. It was seen that they are able to discriminate ions as natural membranes do, and that it is easy to vary their surface charge, in order to modulate the diffusion of a large amount of cations and anions. It was proved that it is possible to incorporate proteins in their lamellar structure and that their composition can be modified to mimic the properties of a large variety of natural membranes. Basically, it was recognized that liposomes are a valuable instrument to study many problems concerning natural membrane structure and function. What's more, it was assumed that, if liposomes were able to incorporate proteins, enzymes, drugs or nucleic acids, an important step towards a true in vitro replica of the membranes of living systems would be obtained.

\subsection{Liposomes and polynucleotide entrapment}

Soon these foreseen opportunities began to turn into actual tasks: liposomes started being applied as carriers of different molecules into target cells (Dimitriadis, 1979; Tyrrell et al., 1976; Finkelstein \& Weissmann, 1978) or of enzymes in enzyme replaced therapy (Gregoriadis \& Buckland, 1973). It was in those years that the entrapment of synthetic polynucleotides (Magee et al., 1976), as well as natural ones (Hoffman et al., 1978; Lurquin, 1979), was undertaken. Large unilamellar liposomes were obtained (Dimitriadis, 1978) by adding ribonucleic acid (globin mRNA) to PS and it was demonstrated that mRNA is really entrapped and not simply adhering to the surface. A different experiment was realized with the aim of clearing up the mechanism of crossing the hydrophobic barriers formed by protein-lipid membranes and the nature of bonds, providing adsorption of polynucleotides in the membranes (a mechanism unknown at that time). It was demonstrated (Budker et al., 1978) that polynucleotides are adsorbed by liposomes of PC forming stable complexes in the presence of $\mathrm{Mg}^{2+}$ or $\mathrm{Ca}^{2+}$ ions, but not in the absence of these ions. This result suggested that this interaction is due to the action of bivalent cations, which crosslink phosphate groups of polynucleotides with the ones of PC. It was also found that the complexes 
obtained are stable, but that the addition of monovalent cations reduces the extent of complexation.

It has been said already that one of the main reasons of the success of cationic liposomes resides in their positive charge that enables attractive interactions both with the negative phosphate groups of the polynucleotides and the negatively charged cell wall. Encapsulation of DNA into a vector is of course the first and irreplaceable step to realize a synthetic vector driven gene therapy and must be solved within neutral liposomes, where the absence of charge does not allow the formation of a stable aggregation with negative DNA. However gene transfer and gene therapy need an efficient encapsulation of plasmid DNA into neutral liposomes and an attractive interaction with the negative cell wall which is the necessary step for the endocytic internalisation of the construct. The methods generally used to realize a stable entrapment can be schematically indicated in three main classes: reverse phase evaporation, dehydration-rehydration and freeze-thawing. According to the first method the nucleic acids are dissolved in water and the solution is added to lipids dispersed in an organic solvent, then evaporated to induce vesiculation (Szoka \& Papahadjopoulos, 1978). In the second procedure the nucleic acids are added to a dispersion of SULs (small unilamellar liposomes) and the mixture is dehydrated until almost dryness; afterwards the material is rehydrated and vortexed to induce the formation of liposomal aggregates (Deamer \& Barchfeld, 1982). The third method involves the addition of nucleic acids to a dispersion of SULs followed by numerous freeze-thawing operations and by a final extrusion to obtain homogeneously sized vesicles (Chapman et al., 1990). The last method was applied to encapsulate a 3368 base pair DNA (Monnard et al., 1997), using liposomes prepared with 1-palmitoyl-2-oleoyl-sn-glycero-3-phosphocholine (POPC) mixed with a little amount of the negative PS or the cationic didodecyl-methylammonium bromide (DDAB) as cosurfatants. The yields of entrapment calculated over the amount of the initial material were 27\% in pure POPC, 26\% in POPC/PS 9:1 and 50\% in POPC/DDAB 99:1. While the addition of PS has evidently no influence on the entrapment, the one of traces of the positive DDAB, doubles the percentage of entrapped DNA. An important contribute to the entrapment of nucleic acids in neutral liposomes was done some years later (Bayley \& Sullivan, 2000). Plasmid DNAs (pDNA) were trapped into pure DOPC, DOPC/DOPE 1:1 and DOPC/DOPE/Chol 1:1:1 by simply adding $\mathrm{CaCl}_{2}$ and ethanol to the initial mixture DNA/lipids. With optimized amounts of ethanol and calcium the entrapment percentages were $65-70 \%$ for DOPC, $70-80 \%$ for DOPC/DOPE $1: 1$ and only $35-40 \%$ for DOPC/DOPE/Chol 1:1:1. Most important the neutral liposome complexes obtained from DOPC and DOPC/DOPE are stable for at least two weeks in PBS (phosphate buffered saline) at $4{ }^{\circ} \mathrm{C}$.

\subsection{Some early experiments of DNA delivery to cells by means of liposomes}

The need of modifying the expression of the eukaryotic genome to study the protein synthesis led to encapsulate a functional rabbit globin mRNA in lecithin liposomes, made by neutral PC and PE, to realize its selective insertion into differentiated eukaryotic cells in vitro and express a globin-like protein (Ostro et al., 1978). The authors claimed this result as the first successful attempt to entrap and deliver high molecular weight RNA with a liposome. New applications followed and led to improve the technique. Poliovirus RNA was encapsulated in liposomes of PS and delivered efficiently to cells in an infectious form 
(Wilson et al., 1979). A comparison between large unilamellar vesicles (LUVs) and multilamellar vesicles (MLVs) of PS indicates that LUVs deliver their content to cell cytoplasm much more efficiently than MLVs and that LUV-entrapped poliovirus RNA produces infection titers 10 to 100 fold higher than when delivered with other techniques. Likewise, DNA isolated from simian virus 40 (SV40) was encapsulated in LUVs of PS and delivered to a monkey cell line (Fraley et al., 1980). The infectivity realized with this method was enhanced at least 100 fold over that of free naked DNA. This process was then used as a probe to study liposome-cell interactions and determine conditions favouring the intracellular delivery of liposome content to cells (Fraley et al., 1981). The efficiency of DNA delivery was found dependent both on size of vesicles and the resistance of liposomes to cell induced leakage of content. Acidic phospholipids are much more effective in both binding and delivery, and PS was found to be the best in both events. Inclusion of cholesterol in liposomes reduces the cell-induced leakage of vesicle content and enhances the delivery of DNA to cells. A brief exposure of cells to glycerol solutions enhances infectivity of the SV40 DNA when encapsulated into the negatively charged liposome of PS, but not in neutral and positively charged liposomes. Morphological studies indicate that the glycerol treatment stimulates membrane vacuolisation and suggest that the enhanced uptake of liposomes occurs by an endocytic-like process. As it was said in a previous paragraph, endocytosis is the mechanism followed in the phase of the internalisation of the complexes liposome/DNA into cells. Additional attempts to transfect DNA to cells by means of bivalent cations mediated complexes of neutral liposomes are reported by the literature (Kovalenko et al., 1996).

\subsection{The problem of the uptake of liposomes by the reticuloendothelial system}

It is known that many liposomes are removed in liver and spleen from the blood circulation within minutes: this property, beneficial when they are employed to carry drugs for treating intracellular infections of the reticuloendothelial system (RES), has limited their use as delivery carriers of material to sites beyond the RES. Designing liposomes with prolonged circulation time requires a reduction of the rate of their clearance by the RES and of the leakage of liposome cargo in blood stream. The search for a solution of the problem has led to the discovery of the so called stealth liposomes, sterically stabilized by the presence of bulky groups: the so-called PEG-liposomes, namely polyethyleneglycol functionalized liposomes, are the most important tools in ensuring a prolonged circulation time in blood. The incorporation of PEG into conventional liposomes provides a steric barrier at the liposome surface that inhibits opsonisation, therefore extending the persistence time of liposomes in the blood. Positive effects are a prolonged circulation lifetime of lipoplexes and a reduced formation of aggregates (Klibanov et al., 1990; Papahadjopoulos et al., 1991). The incorporation of 1,2-dioleoyl-N(methoxy-polyethyleneglycol-succinyl-)phosphatidylethanolamine (PEG-PE) in liposomes composed of egg phosphatidylcholine-cholesterol, exposed to human serum at $37{ }^{\circ} \mathrm{C}$ increases the blood circulation half-life ten times the one of simple phosphatidylcholinecholesterol liposome (Klibanov et al., 1990). While PEG-lipids play an active role in limiting excessive inhibition and fusion during the self-assembling phase when cationic lipids associate with anionic DNA protecting DNA from nuclease degradation in plasma, the steric barrier introduced by PEG is expected to inhibit also the process of fusion with the endosomes and by consequence reduce the transfection activity. Conflicting results have been obtained so far. It has been found (Song et al., 2002) that, owing to the presence 
of PEG lipids with long acyl chains (< 14 carbons), the contact between complexes and endosomal membranes doesn't allow membrane disruption. In general it seems that the biological and physicochemical characteristics of the DNA/copolymer complexes, including PEG, are influenced by the copolymer architecture (Deshpande et al., 2004) and that the transfection efficiency is strongly correlated with the level of cellular association and uptake of the DNA/copolymer complexes.

\subsection{The structure of the complexes of DNA with zwitterionic liposomes}

In previous paragraphs we pointed out that the structure of the lipoplexes represents a fundamental tool in understanding and planning DNA transfection systems. The same remarks are valid for complexes of DNA with neutral (zwitterionic) liposomes in order to evaluate correctly their behaviour and, in case, design the necessary developments to achieve better results in DNA transfection experiments both in vitro and in vivo. These complexes were initially studied in order to understand the influence of DNA structural transition of neutral lipids: DSC thermograms of the DPPC/DNA/Ca ${ }^{2+}$ complex (Tarahovsky et al., 1996) reveal a distinct maximum at the temperature of $316.3 \mathrm{~K}$ in addition to the main maximum at $314.6 \mathrm{~K}$. Since a direct relationship was observed between the molar proportion of DNA in samples and the value of the height of the second peak, it was hence assumed that the higher temperature transition corresponds to the formation of the complex. In another work (Kharakoz et al., 1999) it was demonstrated that DPPC/DNA complexes could be obtained by simply mixing the DNA solutions with an aqueous lipid dispersion in the presence of $\mathrm{Ca}^{2+}$ and that their formation could be obtained with both MLVs and ULVs. The stoichiometry was determined in 4.5 to 5 strongly bound lipid molecules per molecule of nucleotide, depending on the method used in a temperature-scanning ultrasonic study. From this result and the ones obtained in a small angle x-ray scattering experiment (SAXS), a model was proposed (McManus et al., 2003) for the interaction of DNA and DPPC in the presence of $\mathrm{CaCl}_{2}$. The lamellar repeat distance in complexes with MLVs at $298 \mathrm{~K}$ increases slightly as $\mathrm{Ca}^{2+}$ concentration increases, but it drops to a minimum at a $\mathrm{Ca}^{2+}$ concentration equal to $5 \mathrm{mM}$. At this concentration a special compact structural arrangement is observed, indicative of increased order. Combining this finding with the above result on the ratio of 4.5 to 5 lipid molecules per molecule of nucleotide, it was inferred that roughly one $\mathrm{CaCl}_{2}$ binds two DPPC molecules and a model was proposed where every $\mathrm{Ca}^{2+}$ bridges two adjacent DPPC molecules through their phosphate groups. A different possibility was formerly considered (Bruni et al., 1997) in a study on the interactions of bivalent metal cations with double-stranded polynucleotides or DNA and egg yolk PC. Scatchard plots of PC/DNA/ $\mathrm{Mn}^{2+}$ and DNA/ $\mathrm{Mn}^{2+}$ complexes, combined with data of elemental analysis, support an arrangement where each $\mathrm{Mn}^{2+}$ bridges two DNA phosphates with three PC molecules. One more schematic model for interpreting the DNA-lipid interaction mediated by $\mathrm{Ca}^{2+}$ and $\mathrm{Mg}^{2+}$ has been working on the zwitterionic 1,2-dimyristoylphopsphoetyhanolamine (DMPE). Following this suggestion (Gromelski \& Brezesinski, 2006) the divalent cations bridge the negative part of the zwitterionic phospholipid headgroups, thereby making the lipid monolayers positive. Divalent cations also interact with the negative DNA phosphate moieties, condensing the DNA and leading to an ordered alignment of the DNA strands. If not all charges are screened by the divalent cations, the DNA aggregate remains partially negative and can interact either via divalent cations with the lipid phosphate groups or directly with the positively charged ethanolamine groups of DMPE when the lipid phosphate groups are bridged by divalent cations. 


\section{NEUTRAL LIPIDS}

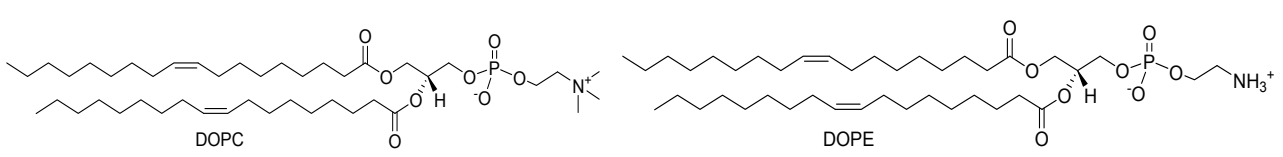

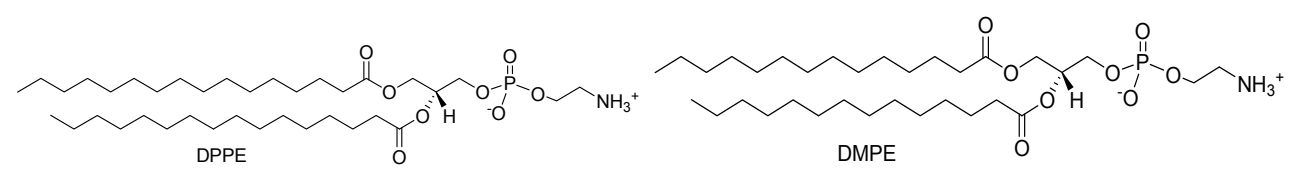

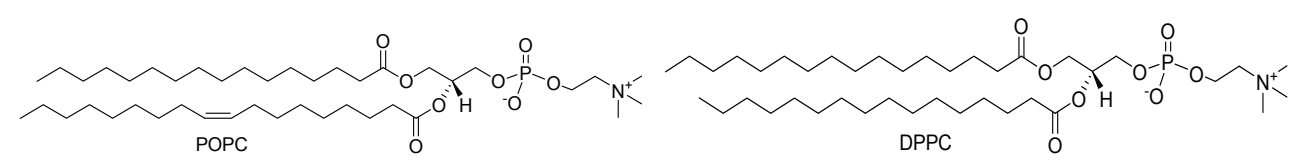

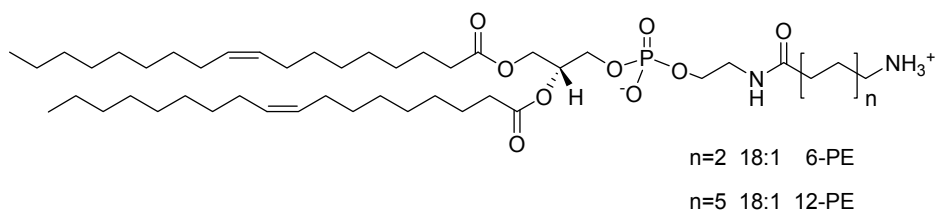

This new class of complexes consists of ternary systems NLs/DNA/ $\mathrm{M}^{2+}$ where $\mathrm{M}$ refers mostly to $\mathrm{Ca}, \mathrm{Mg}$, a choice consistent with the previously reported experiments of membrane fusion, and sometimes $\mathrm{Mn}$. The formation of the ternary complexes is the result of a self assembling process in which the driving force is represented by the release of the counter-ion entropy upon neutralization of DNA phosphate groups by metal cations $(\mathrm{Cl}-$ in the examples discussed). Studies on the structure of these ternary complexes were undertaken mainly by means of $x$-ray diffraction technique.

In all the experiments performed by the authors of this review, XRD measurements were carried out at the high brilliance beamline ID02 of the European Synchrotron Radiation Facility (Grenoble, France). The energy of the incident beam was $12.5 \mathrm{keV}(\lambda=0.995 \AA)$, the beam size $100 \times 100 \mu^{2}$, and the sample-to-detector distance $1.2 \mathrm{~m}$. The $2 \mathrm{D}$ diffraction patterns were collected by a CCD detector. The small angle $\mathrm{q}$ range from $\mathrm{q}_{\min }=0.1 \mathrm{~nm}^{-1}$ to $\mathrm{q}_{\max }=4 \mathrm{~nm}^{-1}$ with a resolution of $5 \times 10^{-3} \mathrm{~nm}^{-1}$ (fwhm) was investigated: the samples were held in a $1 \mathrm{~mm}$-sized glass capillary. To avoid radiation damage, each sample was exposed to radiation for $3 \mathrm{sec} /$ frame. To calculate the electron density maps, the integrated intensities of the diffraction peaks were determined by fitting the data with series of Lorentz functions, using a nonlinear baseline. The Lorentz correction was performed multiplying each integrated intensity by $\sin \theta$ and the intensities were then calibrated dividing by the multiplicity of the reflection (Harper et al., 2001; Francescangeli et al., 1996). The square root of the corrected peak was finally used to determine the modulus of the form factor $F$ of each 
respective reflection. The electron density profile $\Delta \rho$ along the normal to the bilayers was calculated by Fourier sum,

$$
\Delta \rho=\frac{\rho(z)-\langle\rho\rangle}{\left[\left\langle\rho^{2}(z)\right\rangle-\langle\rho\rangle^{2}\right]^{1 / 2}}=\sum_{l=1}^{N} F_{l} \cos \left(2 \pi l \frac{z}{d}\right)
$$

where $\rho(z)$ is the electron density, $\langle\rho\rangle$ its average value, $N$ the highest order of fundamental reflection observed in the SAXS pattern; $F_{l}$ is the form factor of the $(00 l)$ reflection, $d$ the thickness of the repeating unit and the origin of the $z$ axis is chosen in the middle of the lipid bilayers. The phase problem was solved by means of a pattern recognition approach based on the histogram of the electron density map (Tristram-Nagle et al., 1998) and the results were found to be in agreement with those obtained with different approaches.

In a first example (Francescangeli et al., 2003), a DOPC liposome was mixed with calf thymus DNA in hepes buffered aqueous solutions of divalent cations and simultaneous small (SAXS) and wide (WAXS) angle x-ray scattering measurements were carried out.
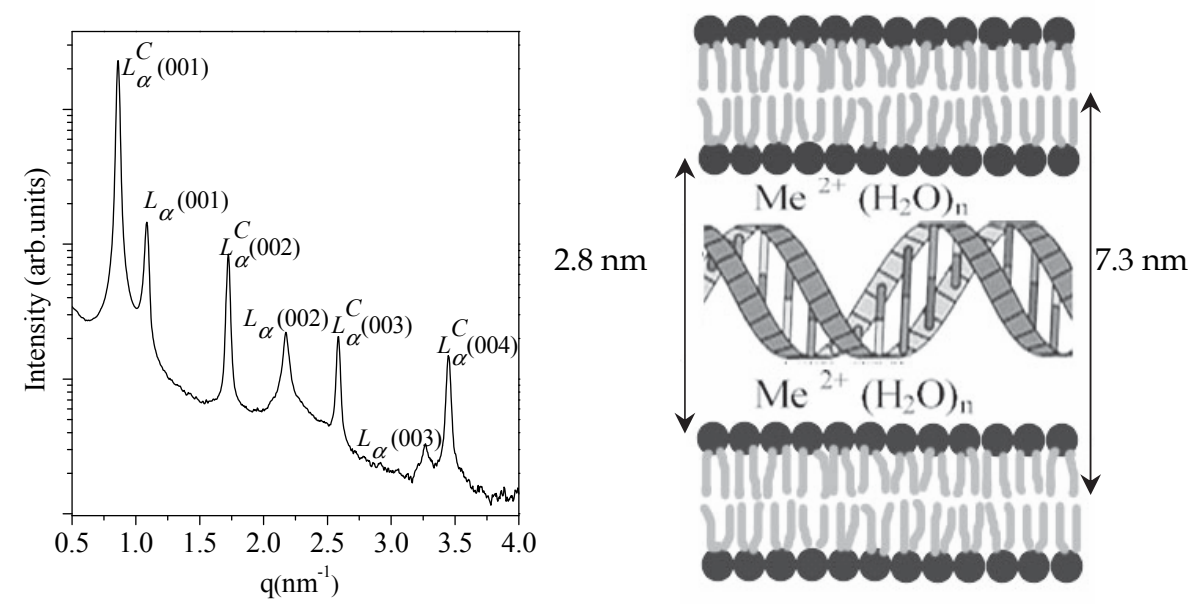

Fig. 2. Left: synchrotron SAXS pattern of DOPC/DNA/ $\mathrm{Mn}^{2+}$ complex at molar ratio 3:4:12. (Reprinted from MROC, 2011, 8, 38) Right: the model proposed for the $\mathrm{L}_{\mathrm{a}}^{\mathrm{C}}$ phase of the ternary complex, reporting the main structural parameters.

In a typical experiment the mole ratio DOPC:DNA:Mn²+ was 3:4:12 and the corresponding synchrotron $x$-ray diffraction (XRD) pattern (Figure 2, left) at $298 \mathrm{~K}$ is reported. Two series of spacings are present in the x-ray pattern: the one indicated with the symbol $L_{\alpha}^{C}(d=7.34$ $\mathrm{nm})$, independent of the concentration of the cation, has been attributed to the ternary complex and the one indicated with the symbol $\mathrm{L}_{\alpha}(\mathrm{d}=5.88 \mathrm{~nm})$ to the complex $\mathrm{DOPC} / \mathrm{Mn}^{2+}$. The ternary complex is characterized by the lamellar symmetry of the $\mathrm{L}_{\alpha}^{\mathrm{C}}$ (Luzzati, 1968), consisting of an ordered multilamellar assembly where the hydrated DNA helices are sandwiched between the liposome bilayers. This structure is similar to that found in CLs/DNA complexes (Rädler et al., 1997; Podgornik et al. 1989). A pictorial representation (Figure 3, left) of the ternary complex DOPC/DNA/ $\mathrm{Mn}^{2+}$ has been proposed: 
the DNA strands are sandwiched between the lipid bilayers and bound together through the hydrated metal ions: the value of $2.8 \mathrm{~nm}$ between two lipid bilayers is sufficient to accommodate a hydrated double strand of DNA (Figure 2, right).
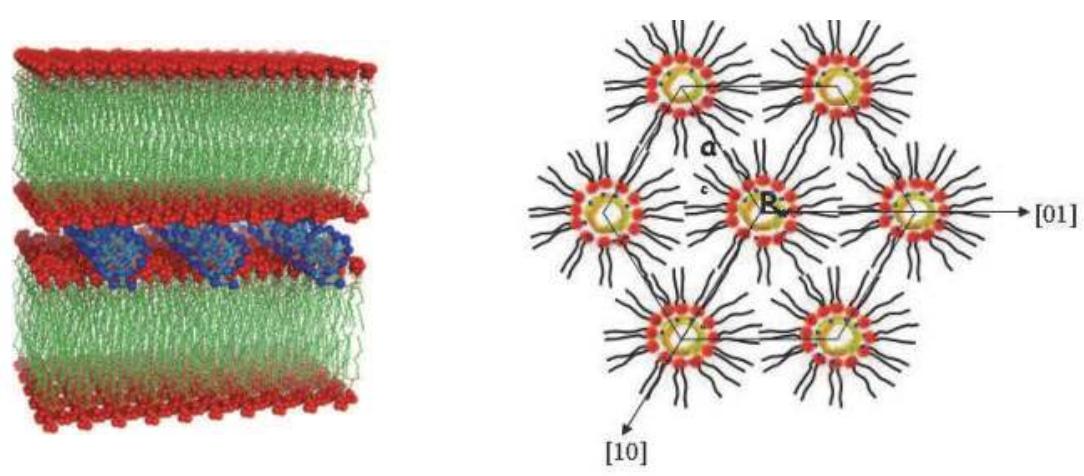

Fig. 3. A pictorial image of the DOPC/DNA/ $\mathrm{Mn}^{2+}$ (left) and of the DOPE/DNA/M²+ (right) ternary complexes.

The simultaneous presence of two lamellar structures, confirmed by an analogous XRD study (Uhrikova et al., 2005), was interpreted by plotting (Figure 4, left) the integrated intensities of the first order diffraction peaks of the DNA complex and of the DOPC liposome as a function of the ratio of the metal ion concentration versus the one of the DNA phosphate groups.
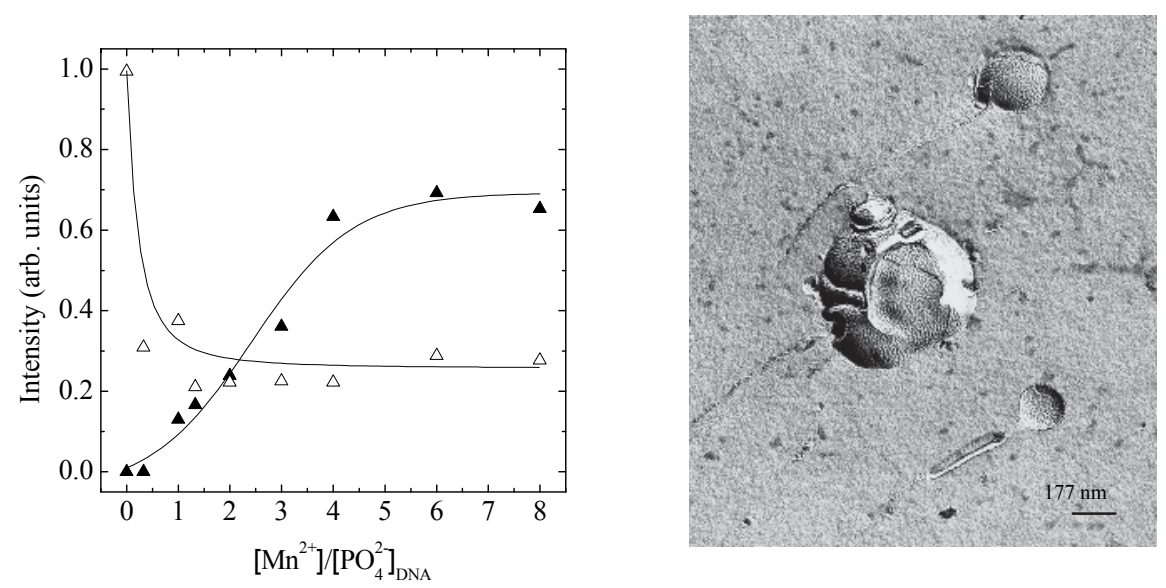

Fig. 4. Left: integrated intensities of the first order diffraction peak of the ternary complex $(\boldsymbol{\Delta})$ and of DOPC liposome $(\triangle)$ as a function of the ratio of the metal ion concentration to the concentration of DNA phosphate groups. (Reprinted from Phys. Rev. E, 2003, 67, 11904). Right: freeze-fracture EM micrograph of the DOPC/DNA/ $\mathrm{Mn}^{2+}$ complex. 
An increase of the $\mathrm{Mn}^{2+}$ concentration favours the formation of the ternary complex accompanied to a complementary reduction of the DOPC: the saturation is reached at a ratio $\left[\mathrm{Mn}^{2+}\right]:\left[\mathrm{PO}_{4}{ }^{2-}\right] \cong 6$, corresponding to a constant volume fraction of the two structures $(\sim 70 \%$ to $\sim 30 \%$ respectively). A freeze-fracture EM micrograph of the ternary complex has also been made and reported in figure 4 (right). An analogous study was made with the neutral liposome 1,2-dipalmitoylphosphatidylcholine (DPPC), bearing completely saturated hydrocarbon tails (McManus et al., 2003) : as for DOPC two coexisting phases are present and the ternary complex shows a lamellar structure, the DNA layers being embedded in the DPPC layers. The repeat distance is $7.84 \mathrm{~nm}$ at $298 \mathrm{~K}$. At this temperature the DPPC/DNA/ $\mathrm{Ca}^{2+}$ complex is in the gel thermotropic phase $\left(\mathrm{L}_{\beta^{\prime}}\right)$.

These works have been followed by an extended approach to ternary complexes based on NLs, bearing unsaturated (DOPC, DLPC and DOPE) or saturated (DPPC) hydrocarbon tails. A twofold goal has been pursued when investigating the microscopic structures of lipids and their corresponding ternary complexes: to test whether different metal cations are equally active in promoting the DNA condensation with different lipids and ascertain to what extent structure and phase symmetry of the lipids affect the structure of the complexes; two aspects that have fundamental implications in view of an approach to gene delivery based application of these complexes. Different varieties of DNA (calf-thymus, salmon sperm and plasmid) complexed with DOPC and DLPC (Pisani et al., 2005) or DPPC (Pisani et al. 2006), in the presence of different cations $\left(\mathrm{Ca}^{2+}, \mathrm{Mn}^{2+}, \mathrm{Co}^{2+}, \mathrm{Fe}^{2+}, \mathrm{Mg}^{2+}\right)$, exhibit the already discussed multilamellar liquid-crystalline $\mathrm{L}_{\mathrm{a}}^{\mathrm{C}}$ phase, consisting of ordered assemblies, where hydrated DNA helices are sandwiched between the lipid bilayers, and the metal cations mediate the binding of the phosphate groups of DNA with the lipid polar heads. Also within these assemblies the $\mathrm{L}_{\mathrm{a}}^{\mathrm{C}}$ phase coexists with the uncomplexed $\mathrm{L}_{\alpha}$ phase of the parent lipid. A systematic series of SAXS measurements in DOPC/DNA $\mathrm{ct}_{\mathrm{ct}} / \mathrm{M}^{2+}$ complexes, prepared with different metal cations, was performed as a function of the number of metal ion moles (n).

The results obtained from these spectra are reported in figure 5: a remarkable constancy of the lamellar spacings of the $\mathrm{L}_{\mathrm{a}}^{\mathrm{C}}$ accompanied by a slight decrease of the lamellar repeat distance of the uncomplexed $\mathrm{L}_{\alpha}$, reported in the figure agrees with the model proposed in figure 3. As an example we report (Figure 6) the analysis of the ternary complex with $\mathrm{Mg}^{2+}$ : again two sets of peaks (each one including fundamental and high-order harmonics) related to distinct lamellar structures $L_{\alpha}^{C}$ and $L_{\alpha}$, with layer spacings $d_{1}=7.52 \mathrm{~nm}$ and $d_{2}=5.9 \mathrm{~nm}$ respectively, are present. The SAXS pattern (A), and the relative electron density profile (B) are shown: in the latter, the two peaks with the maximum of electron density correspond to phospholipids' polar headgroups, while the minimum correlates with the terminal hydrocarbon chain region.

The distance between the centres of the density maxima gives a good approximation of the bilayer thickness $\left(\mathrm{d}_{\mathrm{PP}}=4.51 \mathrm{~nm}\right)$ : it follows that the water-layer thickness can be calculated as $\mathrm{d}_{\mathrm{W}}=\mathrm{d}_{1}-\mathrm{d}_{\mathrm{PP}}=7.52-4.51=3.01 \mathrm{~nm}$ sufficient to accommodate a double stranded DNA helix surrounded by one water hydration layer plus two thin layers of hydrated metal ions. Likewise, it was calculated a water layer thicknesses $d_{W}$ in the range of 2.8-3.0 nm in the complexes with DLPC and in the range of 2.9-3.2 nm in the ones with DPPC, depending on metal cation.

The SAXS pattern of the DPPC/DNA/Ca2+ (Figure 7, left) shows a correlation peak, marked as DNA in the figure, corresponding to the DNA-DNA interaction, indicative of a higher 
organization of the DNA chains between the liposome layers. The thermotropic phase behaviour in a temperature range between $303 \mathrm{~K}$ and $328 \mathrm{~K}$, well above the main transition temperature of the pure lipid $(\mathrm{Tm}=314 \mathrm{~K})$ was studied (Figure 7 , right), leading to the important conclusion that coexistence of complexed and uncomplexed phases persists over the whole explored thermal range. A further relevant effect is observed: while the uncomplexed lipid exhibits the same thermotropic phase behaviour as pure DPPC, i.e. $L_{\beta}$ $-P_{\beta^{\prime}}-L_{\alpha}$, the mesomorphic behaviour of the bound lipid in the complex is partially altered. This is highlighted by the disappearance of the ripple phase and the remarkable increase of the main transition temperature: the observed thermotropic phase sequence of the complex goes directly from $L_{\beta^{\prime}}^{c}$ to $L_{a}^{c}$. (Pisani et al. 2006). In addition the effect of the temperature on the formation of the DOPC/DNA/ $\mathrm{Mn}^{2+}$ complex has been determined (Francescangeli et al., 2003): figure 8 shows the temperature evolution of the XRD patterns of this complex in the range 290 to $320 \mathrm{~K}$ (left) and the temperature dependence (right) of the integrated intensities of the two small-angle reflections for the $L_{\alpha}^{C}$ phase for the ternary complex and the $\mathrm{L}_{\alpha}$ phase of DOPC, respectively.
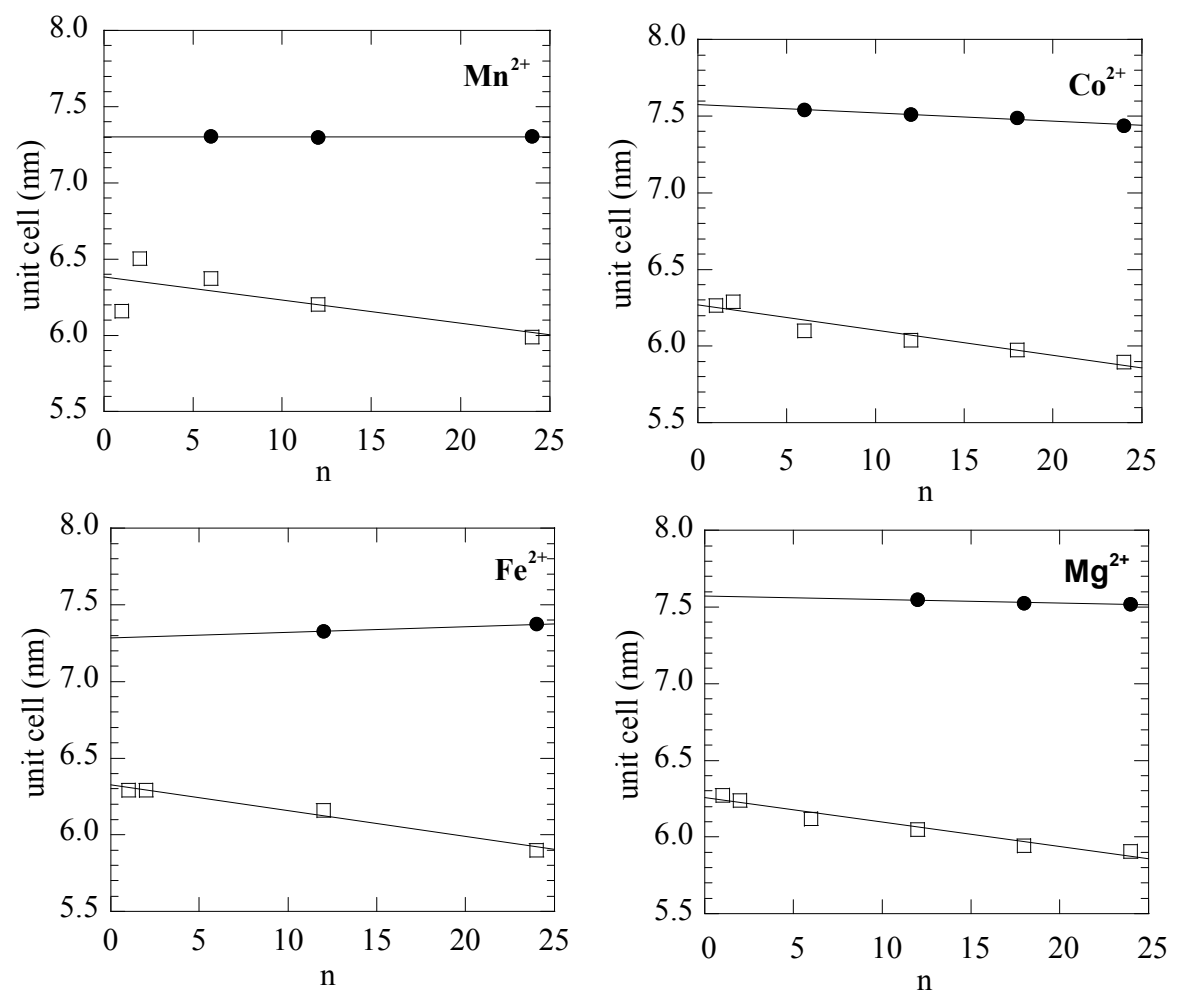

Fig. 5. Lamellar d-spacings of the $\mathrm{L}_{\alpha}^{\mathrm{C}}$ of ternary complex DOPC/DNA $\mathrm{Ac}_{\mathrm{ct}} / \mathrm{M}^{2+}(\bullet)$ and of the $\mathrm{L}_{\alpha}$ phase of DOPC $(\forall)$ as a function of the metal mole number $n$ in the DOPC/DNA complexes at molar ratios 3:4:n. (Reprinted from: M. Pisani, P. Bruni, C. Conti, E. Giorgini, O. Francescangeli. Self-Assembled Liposome-DNA-Metal Complexes Related to DNA Delivery. Mol. Cryst. Liq. Cryst., 2005, 434, 643). 

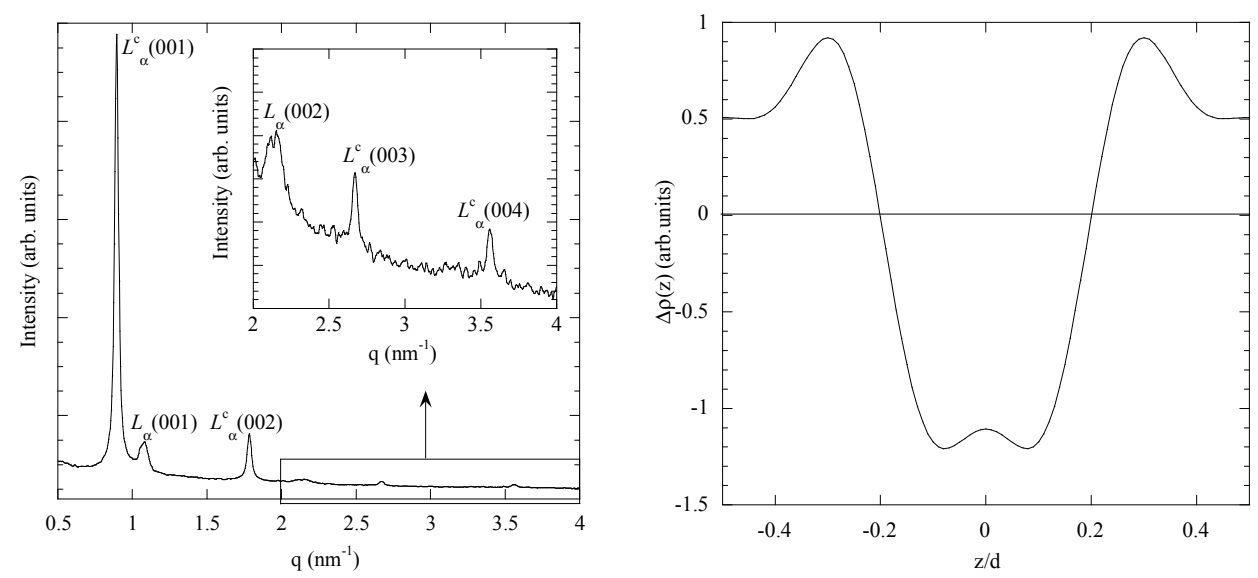

Fig. 6. Left: synchrotron SAXS pattern of the ternary complex DLPC/DNA $\mathrm{Dt}_{\mathrm{ct}} / \mathrm{Mn}^{2+}$ at 3:4:12 molar ratio. Right: electron density profile along the normal to the bilayers in the $\mathrm{L}_{\alpha}^{C}$ phase. (Reprinted from: M. Pisani, P. Bruni, C. Conti, E. Giorgini, O. Francescangeli. SelfAssembled Liposome-DNA-Metal Complexes Related to DNA Delivery. Mol. Cryst. Liq. Cryst., 2005, 434, 643).
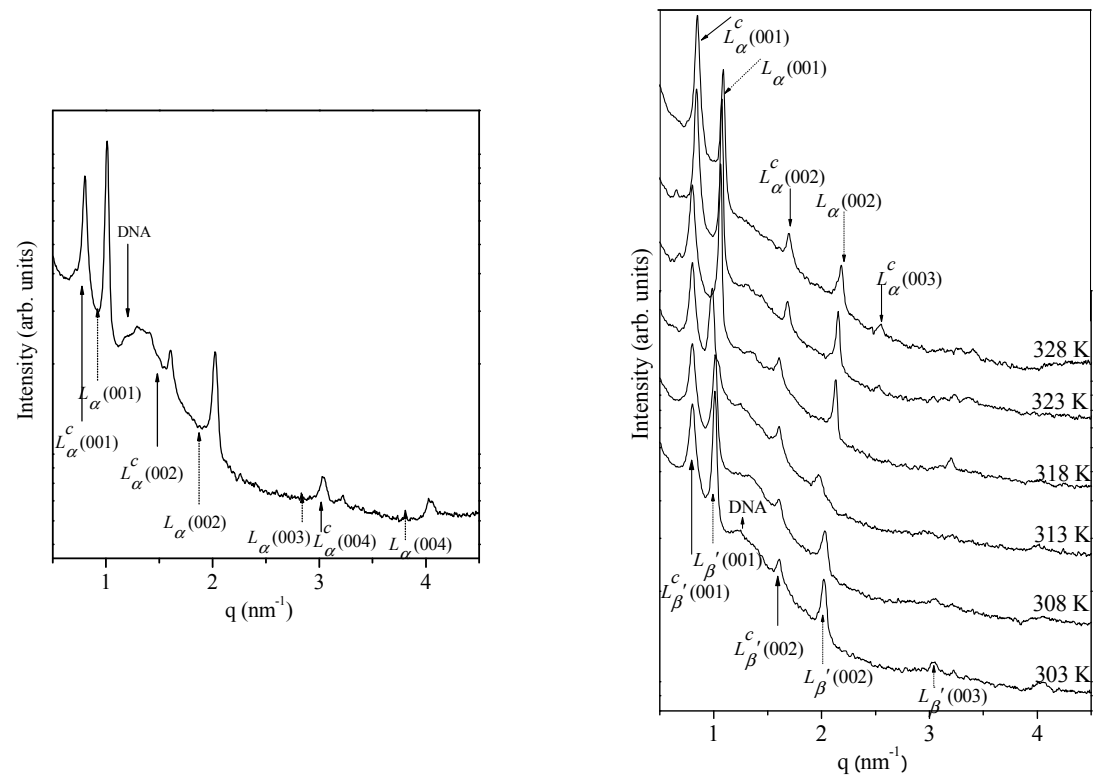

Fig. 7. Left: SAXS pattern of DPPC/DNA/Ca ${ }^{2+}$ complex at molar ratio 3:4:24. Right: synchrotron XRD patterns as a function of temperature. 
The evolution of the equilibrium concentrations of the two phases clearly shows that the increase of the temperature favours the formation of the complex, the relative concentrations of the lamellar phases of pure lipids lowering in favour of the one of the ternary complex.
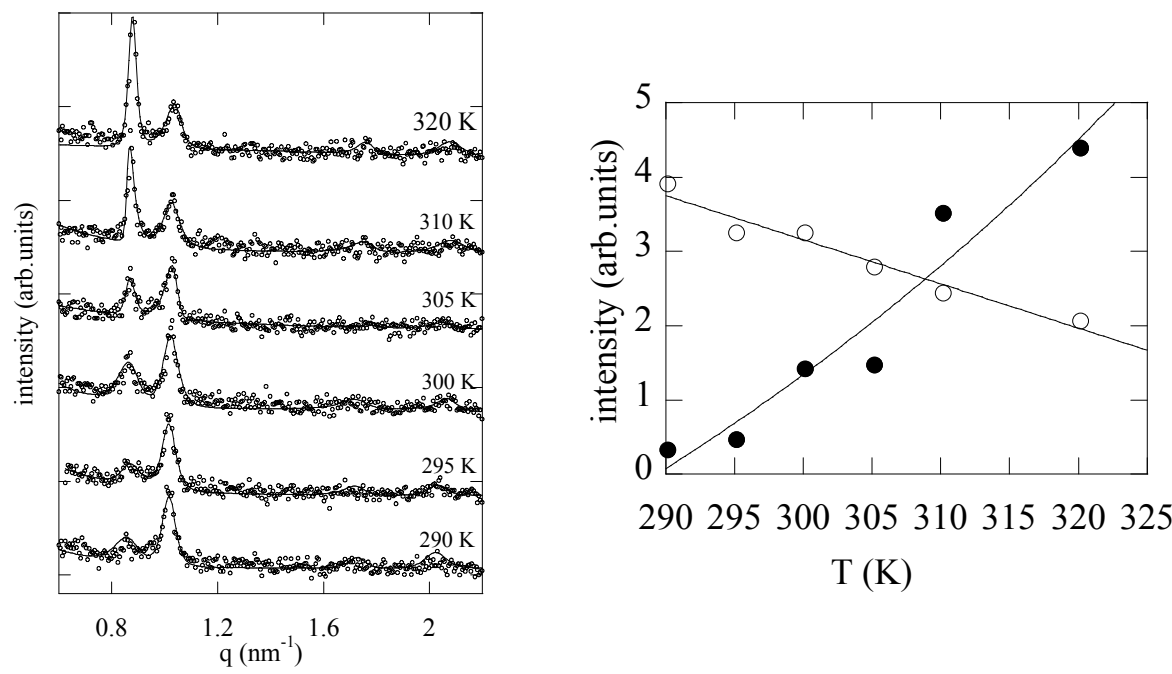

Fig. 8. Left: temperature evolution of the XRD patterns of DOPC/DNA/ $\mathrm{Mn}^{2+}$ in the range 290 to 320 K. Right: temperature dependence of the integrated intensities of the two smallangle reflections for the $\mathrm{L}_{\alpha}^{\mathrm{C}}$ and the $\mathrm{L}_{\alpha}$ phases. (Reprinted from Rec. Res. Devel. in Macromol., 2003, 7, 247).

The complex DOPC/DNA/ $\mathrm{Mn}^{2+}$ has also been studied in a solid supported phase (Caracciolo et al., 2004) by Energy Dispersion X-ray Diffraction (Caminiti \& Rossi Albertini, 1999; Caracciolo et al., 2002) and it has been found that its structure is essentially identical to that in aqueous solution. The effect of hydration on the structural features of these multilamellar systems has also been explored (Caminiti et al., 2005), considering that adsorbed water plays a major role in the effectiveness of lipid drug delivery systems where lipid-cell interactions are involved. The hydration kinetics of oriented DOPC shows that the long-range order in a multilamellar lipid system strictly depends on the hydration level: adsorbed water molecules first promote a spatial coherence along the normal to the lipid bilayers, then penetrate the interbilayer region and behave as bulk water, producing disorder. The existence of a correlation between the degree of hydration of lipid bilayers and the structure of interbilayer water (Ge \& Freed, 2003; Zhou et al., 1999) has been confirmed.

We have already reported that DOPE induces a structural transformation of the lipoplexes when added as a co-lipid: the equilibrium phase of pure DOPE in excess water consists of an inverted hexagonal $\mathrm{H}_{\mathrm{II}}$ lattice (Turner \& Gruner, 1992), whose structure elements are infinitely long rigid rods, all identical and cristallographically equivalent, regularly packed in a 2D hexagonal lattice. The cylinders are filled by water and dispersed in the continuous medium of the hydrocarbon chains, whereas the polar groups are located at the waterhydrocarbon interface. The SAXS pattern of pure DOPE allows to calculate a unit cell 
spacing a $=7.44 \mathrm{~nm}$ (Francescangeli et al., 2004) and its electron density profile calculated along the [10] direction (Figure 9, left) shows an average diameter of the water core $d_{W}=$ $3.02 \mathrm{~nm}$. DOPE and divalent metal cations $\mathrm{Mn}^{2+}, \mathrm{Mg}^{2+}, \mathrm{Co}^{2+}$ and $\mathrm{Fe}^{2+}$ in water solution condense DNA into ternary complexes DOPE/DNA/ $\mathrm{M}^{2+}$ characterized by an invertedhexagonal phase $\mathrm{H}_{\mathrm{II}}^{\mathrm{C}}$. Also in this case two different sets of peaks with different unit cell spacings, namely $\mathrm{a}=7.45 \mathrm{~nm}$ and $\mathrm{a}_{\mathrm{C}}=6.87 \mathrm{~nm}$ respectively, have been observed. The former corresponds to the phase $\mathrm{H}_{\mathrm{II}}$ of pure DOPE, the latter is instead consistent with the 2D columnar inverted hexagonal phase $\mathrm{H}_{\mathrm{II}}^{\mathrm{C}}$ of the DOPE/DNA/ $\mathrm{Fe}^{2+}$ complexes.
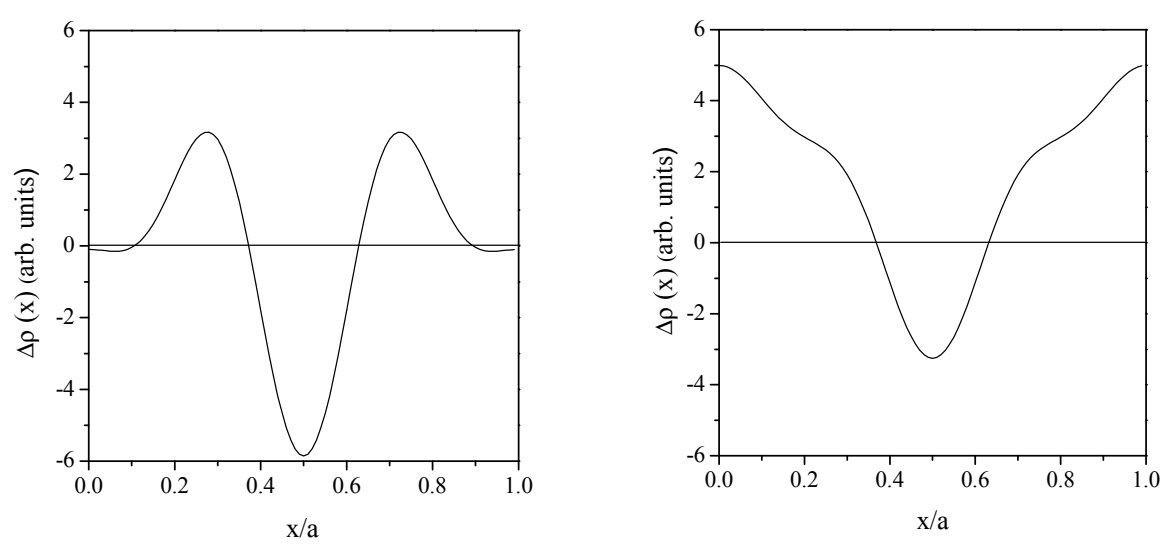

Fig. 9. Left: electron density profile of the pure DOPE along the [10] direction of the unit cell: the origin corresponds to the centre of water core. Right: electron density profile of the complex DOPE/DNA/ $\mathrm{Fe}^{2+}$.

In this structure DNA strands are supposed to fill the water gap inside the cylinders of pure DOPE, as it is supported by the electron density profiles (Figure 9 right) calculated along the [10] direction. The two shoulders, at $\mathrm{z} / \mathrm{d} \sim 0.26$ and 0.73 respectively, correspond to phosphate groups and are used to localize the centres of the polar head. From the structural data, values of $d_{P P}=3.26 \mathrm{~nm}$ and $d_{L}=4.36 \mathrm{~nm}$ were calculated, leading to a water layer thickness $d_{W}=2.51 \mathrm{~nm}$, large enough to accommodate a double-stranded DNA molecule surrounded by a hydration layer (Podgornik et al., 1989). A pictorial representation of this structure is reported in Figure 3 (right). Unlike complexes organized in the $L_{\alpha}^{C}$ the ratio between $\mathrm{H}_{\mathrm{II}}$ and $\mathrm{H}_{\mathrm{II}}^{\mathrm{C}}$ depends also on the incubation time: after 48 hours, phase $\mathrm{H}_{\mathrm{II}}$ disappears completely and is transformed into the $\mathrm{H}_{\mathrm{II}}^{\mathrm{C}}$ of ternary complex.

The effect of pegylation on NLs has also been studied (Pisani at al., 2008, 2009) in mixed complexes DOPE/DOPE-PEG(350)/DNA/ $\mathrm{M}^{2+}(\mathrm{M}=\mathrm{Ca}, \mathrm{Mg}, \mathrm{Mn})$. XRD investigation on the complex with $\mathrm{Mn}^{2+}$ shows that with $3 \%$ of DOPE-PEG, the two phases $\mathrm{H}_{\mathrm{II}}^{\mathrm{C}}$ and $\mathrm{H}_{\text {II }}$ coexist as usual: the former being attributed to DOPE/DOPE-PEG(350)/DNA/ $\mathrm{Mn}^{2+}$, the latter to DOPE/DOPE-PEG(350)/ $\mathrm{Mn}^{2+}$. Interestingly a new phase, indexed in the SAXS pattern as Q (Figure 10), appears at higher concentrations of DOPE-PEG (6, 9 and 15\%): the corresponding peaks are spaced in the ratios $\sqrt{2} ; \sqrt{3} ; \sqrt{4} ; \sqrt{6} ; \sqrt{8} ; \sqrt{9} ; \sqrt{10}$ consistent with a cubic Q224 phase with the space group Pn3m. A transition $\mathrm{H}_{\text {II }} \rightarrow \mathrm{Q}_{\text {II }}$ has been found 
in different contexts (Koynova et al., 1997) : this ability, together with the well known fusogenic property of DOPE and its destabilizing effect on targeted endosomal membranes makes the complexes DOPE/DOPE-PEG(350)/DNA/ $\mathrm{Mn}^{2+}$ extremely interesting for application in HGT.

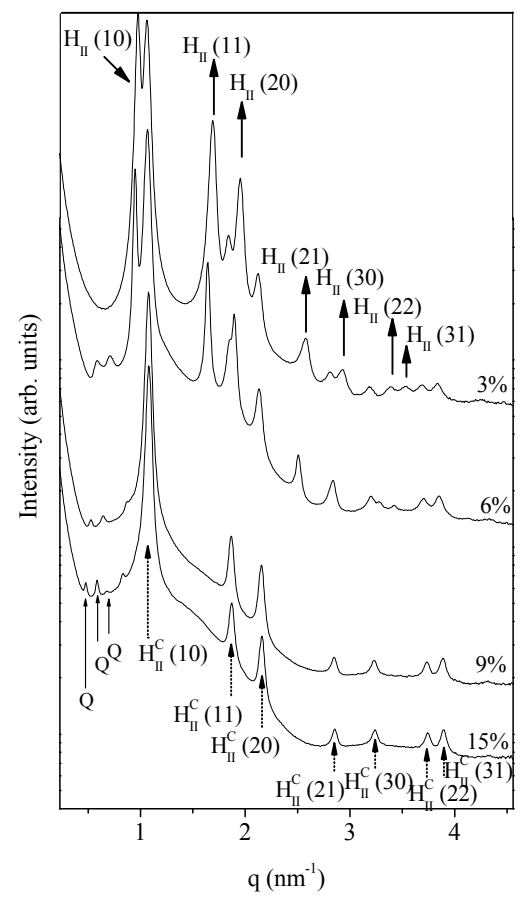

Fig. 10. Synchrotron XRD patterns of the DOPE/DOPE-PEG(350)/DNA/ $\mathrm{Mn}^{2+}$ complex as a function of different concentrations of the DOPE/PEG component in the lipid mixture. The pattern of the cubic phase is clearly visible at $6 \%, 9 \%$ and $15 \%$ concentration of the pegilated DOPE.

\subsection{DNA transfection experiments in vitro}

A first attempt of in vitro transfection was made with a couple of complexes DOPC/pDNA $/ \mathrm{M}^{2+}$, with $\mathrm{M}=\mathrm{Ca}$ or $\mathrm{Mn}$, on a mouse fibroplast NIH 3T3 cell line (Bruni et al., 2006): using standard methods the green fluorescent protein was expressed by both complexes. Figure 11 reports an improved result obtained later, using a $15 \mathrm{mM}$ concentration of $\mathrm{Ca}^{2+}$ in the complex.

Other attempts of in vitro transfections made in our laboratories are compared in a series of histograms (Figure 12) which show that the low efficiency of pure DOPC can be increased by addition of both 1, 2-dioleoyl-sn-glycero-3-phosphoethanolamine-N-hexanoylamine (6PE) or 1,2-dioleoyl-sn-glycero-3-phosphoethanolamine-N-dodecanoylamine (12PE) to DOPC/DNA $/ \mathrm{M}^{2+}$. This result confirms that the transfection efficiency is strongly dependent on an appropriate mixutures of liposomes as DNA carriers. 


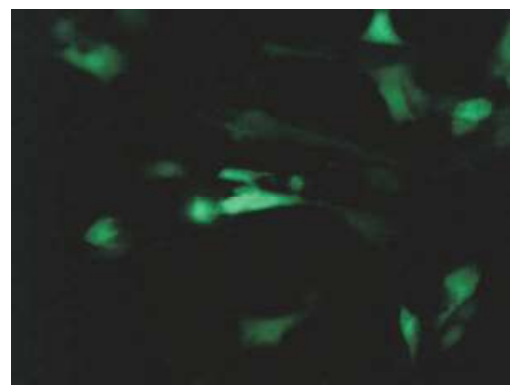

Fig. 11. Fluorescence micrograph of mouse fibroplast NIH 3T3 cells transfected with pGreen Lantern complexed with DOPC liposome in presence of $\mathrm{Ca}^{2+}$.

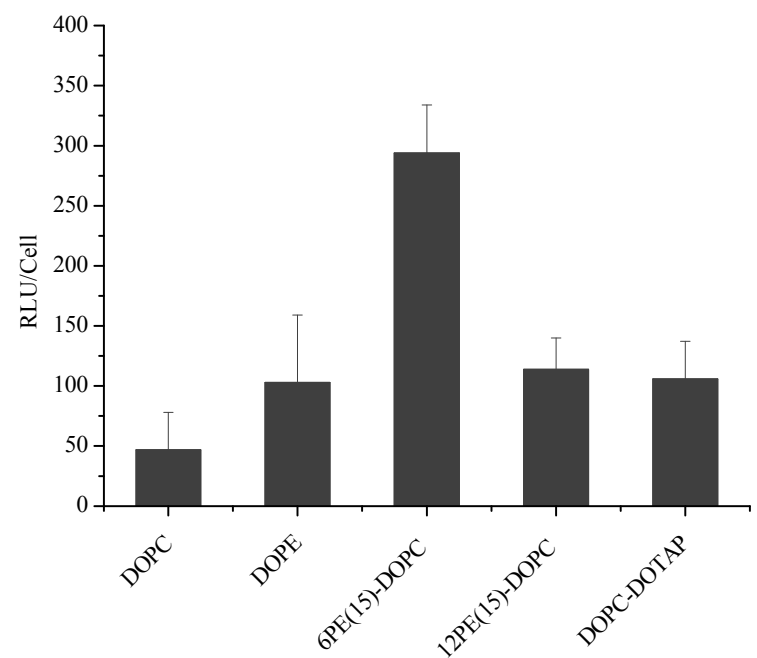

Fig. 12. Luciferase expression following 6hrs transfection with different complexes in NIH3T3 cell line. Expression efficiency is expressed as Relative Luminometric Units per cell (RLU/cell).

An interesting comparison among in vitro transfection efficiencies by DOPE/DNA complexes mediated by cations bearing different charges such as $\mathrm{K}^{+}, \mathrm{Mg}^{2+}, \mathrm{Ca}^{2+}, \mathrm{La}^{3+}$ has been proposed (Tresset et al., 2007). At physiological pH pure DOPE has a slightly negative charge which is not altered by $\mathrm{K}^{+}$owing to its low density of binding sites. On the contrary high charge density has been measured for $\mathrm{Mg}^{2+}$ and $\mathrm{Ca}^{2+}$ and particularly for $\mathrm{La}^{3+}$ (100-fold higher than the two bivalent cations). SAXS of the corresponding ternary complexes show the absence of any ordered structure induced by $\mathrm{K}^{+}$, whereas the usual presence of the two $\mathrm{H}_{\mathrm{II}}$ and $\mathrm{H}_{\mathrm{II}}^{\mathrm{C}}$ phases has been confirmed with the other cations. Transfection efficiency has been measured on the two cell lines U87 and hepG2: due to the absence of a complexation 
by $\mathrm{K}^{+}$, as revealed by $\mathrm{x}$-rays, no transfection has been observed in this case. Instead the efficiency increases in the order $\mathrm{Mg}^{2+}<\mathrm{Ca}^{2+}<\mathrm{La}^{3+}$, the last being 2.6-fold higher than the lipoplex DNA/DOTAP/DOPE. It is also of great importance that the highest efficiency measured with $\mathrm{La}^{3+}$ complex has been obtained with ion concentration of three orders of magnitude lower than that of $\mathrm{Ca}^{2+}$ : a result extremely favourable in relation to toxicity, as it has been proved.

\section{Conclusions and perspectives}

At present the use of NLs as autonomous carriers of genetic material in human gene therapy can be considered an opportunity that needs extensive exploration to become a real alternative to CLs. Considering the many limits the latter still meet, particularly in the in vivo applications, and their slow progress, it seems important to take also the parallel way of NLs as possible autonomous carriers: lack of toxicity and high stability in serum are important characteristics in their favour. Some of the results outlined here are worth interesting developments. It has been found that complexes reflect the structure and symmetry of the parent lipids and that the different bivalent metal cations are equally active in promoting the DNA condensation into the ternary complexes; these achievements will provide structure-composition correlation, that may be used in designing at the best these materials as non-viral DNA carriers in HGT. Additional developments of the research in this field, currently investigated in our laboratories, concern the use of pegylated NLs in the management of brain related diseases, where CLs have started being experimented (Zhang et al., 2002; Pardridge, 2007; Boardo, 2007). Better results could be perhaps obtained with NLs, thanks to their ability to reduce opsonisation. The recent interest in the so-called intelligent carriers which is developing on CLs (Voinea \& Simionescu, 2002; Shi et al., 2002; Alvarez-Lorenzo et al., 2009) could also represent an interesting opportunity for NLs. The structural knowledge of complexes of DNA with NLs is only one of the aspects which will presumably affect the transfection: many other aspects, such as Z-potential values, complex size, and efficient DNA entrapment are all very important acquisitions to be obtained. The entry of NLs in the world of HGT and the consequent opportunity to compare properties and activity with the ones of cationic and anionic liposomes will lead to a better understanding of that processes. In this connection is encouraging to quote the opinion of Rädler, one of the most outstanding experts in cationic lipids: "the resources devoted to creating less toxic cationic-DNA complexes, may perhaps, in the future be balanced by research exploiting the possibility of creating comparable complexes from entirely non toxic components such as the NLs/DNA/M²+ complexes".

\section{References}

Alvarez-Lorenzo, C.; Bromberg, L. \& Concheiro, A. (2009). Light-sensitive intelligent drug delivery systems. Photochem. Photobiol., 85, 848-860, 0031-8655.

Bailay, A.L. \& Sullivan, S.M. (2000). Efficient encapsulation of DNA plasmids in small neutral liposomes induced by ethanol and calcium. Biochim. Biophys. Acta, 1468, 239-252, 005-2736.

Bangham, A.D., Standish, M.M. \& Weissmann, G. (1965). The action of steroids and streptolysin $S$ on the permeability of phospholipids structures to cations. J. Mol. Biol., 13, 253-259, 0022-2836. 
Boado R.J. (2007). Blood-brain barrier transport of non-viral gene and RNAi therapeutics. Pharm. Res., 24, 1772-1787, 0724-8741.

Boukhnikachvili. T., Aguerre-Chariol, O., Airlau, M., Lesieur, S., Ollivon, M: \& Vacus, J. (1997). Structure of in-serum transfecting DNA-cationic lipid complexes. FEBS Lett., 409, 188-194, 0014-5793.

Boussif, O., Lezoualch, F., Zanta, M. A.,. Mergny, M. D., Scherman, D., Demeneix, B.J. \& Behr P. (1995). A versatile vector for gene and oligonucleotide transfer into cells in culture and in vivo: polyethylenimine Proc. Natl. Acad. Sci. USA, 92, 7297-7301, 0027-8424.

Boussif, O., Gaucheron, J., Boulanger, C., Santaella, C., Kolbe, H.V.J. \& Vierling, P. (2001). Enhanced in vitro and in vivo cationic lipid-mediated gene delivery with a fluorinated glycerophospho-ethanolamine. J.Gen. Med., 3, 109-114, 1099-498X.

Bruni, P., Gobbi, G., Morgganti, G., Iacussi, M. \&Maurelli E. (1997). Use and activity of metals in biological systems. The interaction of bivalent metal cations with doublestranded polynucleotides and phospholipids. Gazz. Chim. Ital., 127, 513-517, 00165603.

Bruni, P.; Pisani, M.; Amici, A.; Marchini, C.; Montani, M. \& Francescangeli, O. (2006). Selfassembled ternary complexes of neutral liposomes, deoxyribonucleic acid and bivalent metal cations. Promising vectors for gene transfer? Applied Physics Letters, 88, 73901, 1-3, 0003-6951.

Budker, V. G., Kazatchkov, Y. A. \& Naumova, L. P. (1978). Polynucleotides adsorb on mitochondrial and model lipid membranes in the presence of bivalent cations. FEBS Lett., 95, 143-146, 0014-5793.

Caminiti, R. \& Rossi Albertini, V. (1999). The kinetics of phase transitions observed by energy-dispersive X-ray diffraction. Int. Rev. Phys. Chem., 18, 263-299, 0144-235X.

Caminiti, R.; Caracciolo, G.; Pisani, M. \& Bruni, P. (2005). Effect of hydration on the longrange order of lipid multilayers investigated by in situ time-resolved energy dispersive X-ray diffraction. Chem. Phys. Lett., 409, 331-336, 0009-2614.

Caracciolo, G.; Caminiti, R.; Pozzi, D.; Friello, M.; Boffi, F. \& Congiu Castellano A. (2002). Self-assembly of cationic liposomes-DNA complexes: a structural and thermodynamic study by EDXD. Chem. Phys. Lett., 351, 222-228, 0009-2614.

Caracciolo, G.; Sadun, C.; Caminiti, R.; Pisani, M.; Bruni, P. \& Francescangeli, O. (2004). Structure of solid-supported lipid-DNA-metal complexes investigated by energy dispersive X-ray diffraction. Chem. Phys. Lett., 397, 138-143, 0009-2614.

Caracciolo, G. \& Caminiti, R. (2005). Do DC-Chol/DOPE-DNA complexes really form an inverted hexagonal phase? Chem. Phys. Lett., 411, 327-332, 0009-2614.

Chapman, C.J., Erdahl, W.L., Taylor, R.W. \& Pfeiffer, D.R. (1990). Factors affecting solute entrapment in phospholipid vesicles prepared by the freeze-thaw extrusion method: a possible general method for improving the efficiency of entrapment. Chem. Phys. Lipids, 55, 73-83, 0009-3084.

Deamer, D.W. \& Barchfield, G.L. (1982). Encapsulation of macromolecules by lipid vesicles under simulated prebiotic conditions. J.Mol. Evol., 18, 203-206, 0022-2844.

Deshpande, M.C.; Davies, M.C.; Garnett, M.C.; Williams, P.M.; Armitage, D.; Bailey, L.; Vamvakaki, M.; Armes, S.P. \& Stolnik, S. (2004): The effect of poly(ethylene glycol) molecular architecture on cellular interaction and uptake of DNA complexes. $J$. Control. Release, 97, 143-156, 0168-3659. 
Dimitriadis, G.J. (1978). Entrapment of ribonucleic acid in liposomes. FEBS Lett., 86, 289-293, 0014-5793.

Dimitriadis, G.J. \& Butters, T.D. (1979). Liposome-mediated ricin toxicity in ricin-resistant cells. FEBS Lett., 98, 33-36, 0014-5793.

Düzgünes, N., Wilschut, J., Fraley, R. \& Papahadjopoulos, D. 1981. Studies on the mechanism of membrane fusion. Role of head-group composition in calcium- and magnesium-induced fusion of mixed phospholipid vesicles. Biochim. Biophys. Acta, 642, 182-195, 0005-2736.

Edelstein, M.J., Abedi, M.R., Wicson, J. \& Edelstein, M.R. (2004): Gene therapy clinical trials worldwide 1989-2004. J. Genet. Med., 6, 597-602, 1226-1769.

Elouahabi, A. \& Ruysschaert, J.M. (2005). Formation and intracellular trafficking of lipoplexes and polyplexes. Mol. Ther., 11, 336-347, 1525-0016.

Farhood, H., Serbina, N. \& Huang, L. (1995), The role of dioleyl phosphatidylethaloamine in cationic liposome- mediated gene transfer. Biochim. Biophys. Acta, 1235, 289-295, 0005-2736.

Fasbender, A., Marshall, J., Moninger, T.O., Grust, T., Cheng, S. \& Welsh, M.J. (1997). Effect of co-lipids in enhancing cationic-lipid mediated gene transfer in vitro and in vivo. Gen. Ther., 4, 716-725, 0969-7128.

Felgner, P.L., Gadek,T.R., Holm, M., Roman, R., Chan, H.W., Wenz, M., Northrop, J.P., Ringold, G.M. \& Danielsen, M. (1987). Lipofection: A highly efficient, lipidmediated DNA-transfection procedure. Proc. Natl. Acad. Sci. USA, 84, 7413-7417, 0027-8424.

Felgner, J.H., R Kumar, C N Sridhar, C J Wheeler, Y J Tsai, R Border, P Ramsey, M Martin, \& P L Felgner. (1994). Enhanced gene delivery and mechanism studies with a novel series of cationic lipid formulations. J. Biol. Chem., 269, 2550-2561, 0021-9258.

Filion, M.C., Phillips, N.C. (1998). Major limitations in the use of cationic liposomes for DANN delivery. Int. J. Pharm., 162, 159-170, 0378-5143.

Finkelstein, M. \& Weissmann, G. (1978). The introduction of enzymes into cells by means of liposomes. J. Lip. Res., 19, 289-303, 0022-2275.

Fletcher S., Ahmad, A., Perouzel, E., Jorgensen \& M.R., Miller, A.D. (2006). A dialkynoyl analog of DOPE improves gene transfer of lower-charged cationic lipoplexes. Org. Biomol. Chem., 4, 196-199, 1477-0520.

Foradada, M.; Pujol, M.D.; Bermudez, J. \& Esterlich, J. (2000). Chemical degradation of liposomes by serum components detected by NMR. Chem. Phys. Lipids, 104, 133-148, 0009-3084.

Fraley, R., Subramani, S., Berg, P. \& Papahadjopoulos, D. (1980). Introduction of liposomeencapsulated SV40 DNA into cells. J. Biol. Chem., 255, 10431-10435, 0021-9258.

Fraley, R., Straubinger, R.M., Rule, G., Springer, A.L. \& Papahadjopoulos, D. (1981). Liposome-mediated delivery of deoxyribonucleic acid to cells: enhanced efficiency of delivery related to lipid composition and incubation conditions. Biochemistry, 20, 6978-6987, 0006-2960.

Francescangeli, O.; Rinaldi, D.; Laus, M.; Galli, G. \& Gallot, B.J. (1996). An X-ray study of a smectic $\mathrm{C}$ and smectic A liquid crystal polyacrylate. J. Phys. II, 6, 77-89.

Francescangeli, O., Pisani, M., Stanic, V., Bruni, P. \& Iacussi, M. (2003). Supramolecular ordering of self-assembled liposome-DNA- metal complexes. Recent Res. Dev. Macromol. Res., 7, 247-263, 81-271-0025-0. 
Francescangeli, O., Stanic, V., Gobbi, L., Bruni, P., Iacussi, M., Tosi, G. \& Bernstorff, S. (2003). Structure of self-assembled liposome-DNA-metal complexes. Phys. Rev. E, 67, 11904 (1-11), 1539-3755.

Francescangeli, O.; Pisani, M.; Stanic, V.; Bruni, P. \& Weiss, T.M. (2004). Evidence of an inverted hexagonal phase in self-assembled phospholipid-DNA-metal complexes. Europhysics Letters, 67, 669-675, 0295-5075.

Gaucheron, J., Santaella, C. \& Vierling, P. (2001a). Higly fluorinated lipospermines fo gene transfer: synthesis and evaluation of their in vitro transfection efficiency. Bioconj. Chem., 12, 114-128, 1043-1802.

Gaucheron, J., Santaella, C. \& Vierling, P. (2001b). Improved in vitro gene transfer mediated by fluorinated lipoplexes in the presence of a bile salt surfactant. J.Gene Med., 3, 338344, 1029-498X..

Gaucheron, J., Boulanger, C., Santaella, C., Sbirrazzuoli, N., Boussif. O. \& Vierling, P. (2001c). In vitro cationic lipid-mediated gene delivery with fluorinated glycerophosphoethanolamine helper lipids. Bioconj. Chem., 12, 949-963, 1043-1802.

Ge, M. \& Freed J.H. (2003). Hydration, structure and molecular interactions in the headgroup region of dioleoylphosphatidylcholine bilayers: an electron spin resonance study. Biophys. J., 85, 4023-4040, 006-3495.

Gregoriadis, G. \& Buckland R. A. (1973). Enzyme-containing Liposomes alleviate a Model for Storage Disease. Nature, 244, 170-172, 0038-0836.

Gromelski, S. \& Brezezinski, G. (2006). DNA condensation and interaction with zwittrionic phospolipids mediated by divalent cations. Langmuir, 22, 6293-6301, 0743-7463.

Hacein-Bey-Abina, S. et al. (2003). LMO2-Associated clonal T cell proliferation in two patients after gene therapy for SCID-X1. Science, 302, 415-419, 0036-8075.

Harper, P. E.; Mannock, D.A.; Lewis, R.N.A.H.; McElhaney, R.N. \& Gruner, S.M. (2001). XRay diffraction structures of some phosphatidylethanolamine lamellar and inverted hexagonal phases. Biophys. J., 81, 2693-2706, 0006-3495.

Harrington, J.J., Van Bokkelen, G., Mays, R.W., Gustashaw, K. \& Williard, H.F. (1997). Formation of de novo centromeres and construction of first-generation human artificial microchromosome. Nat. Genet., 15, 345-355, 1061-4036.

Hoffman, R.M., Margolis, R.B. \& Bergelson, L.D. (1978). Binding and entrapment of high molecular weight DNA by lecithin liposomes. FEBS Lett., 93, 365-368, 0014-5793.

Kharakoz, D.P., Khusainova, R.S., Gorelov, A.V. \& Dawson, K.A. (1999). Stoichiometry of dipalmitoylphosphatidylcholine-DNA interaction in the presence of $\mathrm{Ca}^{2+}$ : a temperature-scanning ultrasonic study. FEBS Lett., 466, 27-29, 0014-5793.

Klibanov, A.L., Maruyama, K:, Torchilin, V.P. \& Huang, L. (1990). Amphipatic polyethylenglycos effectively prolong the

circulation time of liposomes. FEBS, 268, 235-237, 0014-5793.

Koiv, A., Palvimo, J. \& Kinnunen, P.K. (1995). Evidence for ternary complex by histone H1, DNA and liposomes. Biochemistry, 34, 8018-8027, 0006-2960.

Koltover, L., Salditt, T., Rädler, J.O. \& Safinya, C.R. (1998). An inverted hexagonal phase of cationic liposome-DNA complexes related to DNA release and delivery. Science, 281, 78-81, 0036-8075.

Kostarelos, K. \& Miller, A.D. (2005). Synthetic, self-assembly ABCD nanoparticles; a structural paradigm for synthetic non-viral vectors. Chem. Soc. Rev., 34, 970-994, 0306-0012. 
Kovalenko D.V.; Shafei, R.A.; Zelenina, I.A.; Semenova, M.L.; Samuilova, O.V. \& Zhdanov, R.I. (1996). Metallo nucleoliposome complexes as a vehicle for gene delivery to mouse skeletal muscles in vivo. Genetika, 32, 1299-1301, 1022-7954.

Koynova, R.; Tenchov, B. \& Rapp, G. (1997). Low amounts of PEG-lipid induce cubic phase in phosphatidylethanolamine dispersions. Biochim. Biophys. Acta, 1326, 167-170, 0005-2736.

Koynova, R., Wang, L., Tarahovsky, W. \& McDonald, R.C. (2005). Lipid phase control of DNA delivery. Bioconj. Chem., 16, 1335-1339, 1043-1802.

Koynova, R., Wang, Li. \& MacDonald, R.C. (2006). An intracellular lamellar-non lamellar phase transition rationalizes the superior performance of some cationic lipid transfection agents. Proc. Natl. Acad. Sci. USA, 103, 14373-14378, 0027-8424.

Lin, A.J., Slack, N.L., Ahmad, A., George, C.X., Samuel, C.E. \& Safinya, C.R. (2003). Threedimensional imaging of lipid gene-carriers: membrane charge density controls universal transfection behavior in lamellar cationic liposome-DNA complexes Biophys. J., 84, 3307-3316, 0006-3495.

Liu, F. \& Huang, L. (2002). Development of non-viral vectors for systemic gene delivery. J. Control. Rel., 78, 259-266, 0168-3659.

Lurquin, P.F. (1979). Entrapment of plasmid DNA by liposomes and their interactions with plant protoplast. Nucleic Acid Res., 6, 3773-3784, 0305-1048.

Luzzati, V. (1968). Biological Membranes, Academic Press, New York, London.

Lv, H., Zhang, S., Wang,B., Cui, S. \& Yan, J. (2006). Toxicity of cationic lipids and cationic polymers in gene delivery. J.Control. Rel., 114, 100-109, 0168-5659.

Magee, W., Talcott, M., Straub, S. \& Vriend, D. (1976). A comparison of negatively and positively charged liposomes containing entrapped polynosinic polycytidylic acid for interferon induction in mice. Biochim. Biophys. Acta, 451,610-618, 0304-4165.

Marshall, E. (2000). Gene Therapy on Trial. Science, 288, 951-957, 0036-8075.

McDonald, R.C., Ashley, G.W., Shida M.M., Rakhmanova, V.A., Tarahovsky, Y.S., Pantazatos, P.P., Kennedy, M.T., Pozharski, E.V., Baker, K.A., Jones, R.D., Rosenzweig, H.S., Choi, K.L., Qiu, R.Z. \& McIntosh T. J. (1999). Physical and Biological Properties of cationic triesters of phosphatidylcholine. Biophys. J., 77, 2612-2629, 0006-3495.

McManus, J.J., Rädler, J.O. \& Dawson, K.A. (2003). Does calcium turn a zwitterionic lipid cationic? J. Phys. Chem. B, 107,

9869-9875, 1520-6106.

McManus, J.J., Rädler, J.O. \& Dawson, K.A. (2003). Phase behavior of DPPC in a DNAcalcium-zwitterionic lipid complex studied by small-angle $\mathrm{x}$-ray scattering. Langmuir, 19, 9630-9637, 0743-7463.

Mével, M., Neveu, C., Goncalves, C., Yaouanc, J.J., Pichon, C., Jaffrès, P.A. \& Midoux, P. (2008). Novel neutral imidazole-lipophosphoramides for transfection assays. Chem Comm., 3124-3126, 1359-7345.

Mok, K.W. \& Cullis, P.R. (1997). Structural and fusogenic properties of cationic liposomes in the presence of plasmid DNA. Biophys. J., 73, 2534-2545, 0006-3495.

Monnard, P.A., Oberholzer, T. \& Luisi, P.L. (1997). Entrapment of nucleic acids in liposomes. Biochim. Biophys. Acta, 1329, 39-50, 0005-2736. 
Mui, H., Ahkong, Q.F., Chow, L. \& Hope, M.J. (2000). Membrane perturbation and the mechanism of lipid-mediated transfer of DNA into cells. Biochim. Biophys. Acta, 1467, 281-292, 0005-2736.

Newton, C., Pangborn, W, Nir, S. \& Papahadjopoulos, D. (1978). Specificity of $\mathrm{Ca}^{2+}$ and $\mathrm{Mg}^{2+}$ binding to phsphatidylserine vesicles and resultant phase changes of bilayer membrane structure. Biochim. Biphys. Acta, 506, 281-287, 0005-2736.

Ostro, M.J., Giacomini, D., Lavelle, D., Paxton, W. \& Dray, S. (1978). Evidence for traslation of rabbit globin mRNA after liposome mediated insertion into a human cell line. Nature, 274, 921-923, 0028-0836.

Papahadjopoulos, D., Vail, W.J., Pangborn, W. \& Poste, G. (1976). Studies on membrane fusion. II. Induction in fusion in pure phospholipid membranes by calcium ions an other divalent metals. Biochim. Biophys. Acta, 448, 265-283, 0005-2736.

Papahadjopoulos, D.; Allen, T.M.; Gabizon, A.; Mayhew, E.; Matthay, K.; Huang, S.K.; Lee, K.D.; Woodle, M.C.; Lasic, D.D.; Redemann, C. \& Martin, F.J. (1991). Sterically stabilized liposomes: improvements in pharmacokinetics and antitumor therapeutic efficacy. Proc. Natl. Acad. Sci. USA, 88, 11460-11464, 0027-8424.

Pardridge, W.M. (2007). shRNA and siRNA delivery to the brain. Adv. Drug Del. Reviews, 59, 141-152, 0169-409X..

Pisani, M., Bruni, P., Conti, C., Giorgini, E. \& Francescangeli, O. (2005). Self.-asembled liposome-DNA metal complexes related to DNA delivery. Mol. Cryst. Liq. Cryst., 434, 315-323, 1542-1406.

Pisani, M., Bruni, P., Caracciolo, G., Caminiti, R. \& Francescangeli, O. (2006). Structure and phase behavior of self-assembled DOPC-DNA-Metal Cation complexes. J. Phys. Chem. B, 110, 13203-13211, 1520-6106.

Pisani, M., Fino, V., Bruni, P., Di Cola, E. \& Francescangeli, O. (2008). Metal induced cubic phase in poly(ethyleneglycol)-functionalized dioleoylphosphatidylethanolamine aqueous dispersions. J. Phys. Chem. Letters B, 112, 5276-5278, 1520-6106.

Pisani, M., Fino, V., Bruni, P. \& Francescangeli, O. (2009). DNA condensation into inverted hexagonal phase in aqueous dispersion of poly(ethylene)-functionalized dioleoylphosphatidylethanolamine and metal cations. Mol. Cryst. Liq. Cryst., 500, 132-143, 1542-1406.

Podgornik, R., Rau, D.C. \& Parsegian, V.A. (1989). The action of interhelical forces on the organisation of DNA double helices: fluctuation-enhanced decay of electrostatic double-layer and hydration forces. Macromolecules, 22, 1780-1786, 0024-9297.

Portis, A., Newton, C., Pangborn, W. \& Papahadjopoulos, D. (1979). Studies on the mechanism of membrane fusion: Evidence for an intermembrane $\mathrm{Ca}^{2+}$ phospholipid complex, synergism with $\mathrm{Mg}^{2+}$ and inhibition by spectrin. Biochemistry, 18, 780-790, 0006-2960.

Rädler, J.O., Koltover, I., Salditt, T. \& Safinya, C.R. (1997). Structure of DNA-Cationic liposome complexes: DNA intercalation in multilateral membranes in distinct interhelical packing regimes. Science, 275, 810-814, 0036-8075.

Roush, W. (1997). Molecular biology: counterfeit chromosomes for humans. Science, 276, 3839, 0036-8075.

Safinya, C.R., (2001). Structures of lipid-DNA complexes: supramolecular assembly and gene delivery. Curr. Opin. Struct. Biol., 11, 440-448, 0959-440X. 
Safinya, C.R., Ewert, K., Ahmad, A., Evans, H.M., Raviv, U., Needleman, D.J., Lin, A.J., Slack, N.L., George, C. \& Samuel, C.E. (2006). Cationic liposome-DNA complexes: from liquid crystal science to gene delivery applications. Phil. Trans. R. Soc. A, 364, 2573-2596, 1364-503X

Sessa, G. \& Weissmann, G. (1968). Phospholipid spherules (liposomes) a model for biological membranes. J. Lipid Res., 9, 310-318, 0022-2275.

Shi, G., Guo, W., Stephenson, S.M. \& Lee, R.J. (2002). Efficient intracellular drug and gene delivery using folate receptor-targeted $\mathrm{pH}$-sensitive liposomes composed of cationic/anionic lipid combinations. J. Control Rel., 80, 309-319, 0168-3659.

Song, L.Y., Ahkong, Q.F.; Rong, Q., Wang, Z., Ansell, S., Hope, M.J. \& Mui, B. (2002). Characterization of the inhibitory effect of PEG-lipid conjugates on the intracellular delivery of plasmid and antisense DNA mediated by cationic lipid liposomes. Biochim. Biophys. Acta, 1558, 1-13, 005-2736.

Szoka, F. \& Papahadjopoulos, D. (1978). Procedure for preparation of liposomes with large internal aqueous space and high capture by reverse-phase evaporation. Proc. Natl. Acad. Sci. USA, 75, 4194-4198, 0027-8424.

Szoka, F.C.,Jr., Xu, Y. \& Zelphati, O. (1996). How are nucleic acids released in the cell from cationic-nucleic acid complexes. J. Liposome Res., 6, 567-587, 0898-2104.

Tarahowsky, Y.S., Khusainova, R.S., Gorelov, A.V., Nicolaeva, T.I., Deev, A.A., Dawson, A.K. \& Ivanitsky, G.R. (1996).

DNA initiates polymorphic structural transitions in lecithin. FEBS Lett., 390, 133-136, 00145793.

Tardi, P.G., Boman, N.L. \& Cullis, P.R. (1996). Liposomal doxorubicin. J. Drug Target., 4, 129-140, 1061-186X.

Tresset, G., Cheong, W.C.D., Tan, Y.L.S., Boulaire, J. \& Lam, Y.M. (2007). Phospholipid based artificial viruses assembled by multivalent cations. Biophys. J., 93, 637-644, 0006-3495.

Tristram-Nagle, S.; Peytrache, H.I. \& Nagle, J.F. (1998). Structure and interactions of fully hydrated dioleoylphosphatidylcholine bilayers. Biophys. J., 75, 917-925, 0006-3495.

Turner, D.C. \& Gruner, S.M. (1992). X-ray diffraction reconstruction of the inverted hexagonal $\left(\mathrm{H}_{\mathrm{II}}\right)$ phase in lipid-water systems. Biochemistry, 31, 1340-1355, 0006-2960.

Tyrrell, D.A., Heath, T.D., Colley, C.M. \& Ryman, B.E. (1976). New aspects of liposomes. Biochim. Biophys. Acta, 457, 259-302, 0005-2736.

Uhrikova, D., Hanulova, M.; Funari, S.S., Khusainova, R.S., Sersen, F., Balgavy, P. (2005). The structure of DNA-DOPC aggregates formed in presence of calcium and magnesium ions: a small-angle synchrotron X-ray diffraction study. Biochim: Biophys. Acta, , 1713, 15-28, 005-2736.

Voinea, M. \& Simionescu, M. (2002). Designing of intelligent liposomes for efficient delivery of drugs. J. Cell. Mol. Med., 6, 465-474, 1582-1838.

Willard, H.F. (2000). Artificial Chromosomes Coming to Life. Science, 290, 1308-1309, 00368075.

Wilschut, J., Düzgünes, N., Fraley, R. \& Papahadiopoulos, D. (1980). Studies on the mechanism of membrane fusion: kinetics of calcium ion induced fusion of phosphatidylserine vesicles followed by a new assay for mixing of aqueous vesicle contents. Biochemistry, 19, 6011-6021, 0006-2960. 
Wilson, T., Papahadjopoulos, D. \& Taber, R. (1979). The introduction of poliovirus DNA into cells via lipid vesicles (lipoosmes). Cell, 17, 77-84, 0092-8674.

Worthington, C.R. \& Khare, R.S. (1978). Structure determination of lipid bilayers. Biophys. J., 23, 407-425, 0006-3495.

Wrobel, I. \& Collins, D. (1995). Fusion of cationic liposomes with mammalian cells occurs after endocytosis. Biochim. Biophys. Acta, 1235, 296-304, 0005-2736.

Wu, G.Y. \& Wu; C.H. (1987). Receptor-mediated in vitro gene transformation by a soluble DNA carrier system.. J. Biol. Chem., 262, 4429-4432, 0021-9258.

Yang, J.P. \& Huang, L. (1997). Overcoming the inhibitory effect of serum on lipofection by increasing the charge ratio of cationic liposome to DNA. Gen. Ther., 4, 950-960, 09697128 .

Zelphati, O. \& Szoka F.C. (1996). Liposomes as a carrier for intracellular delivery of antisense olinucleotides: a real or magic bullet? J. Control. Rel., 41, 99-119, 0168-3659.

Zhang, Y., Zhu, C. \& Pardridge W.M. (2002). Antisense gene therapy of brain cancer with an artificial virus gene delivery system. Mol. Ther., 6, 67-72, 1525-0016.

Zhou, Z., Sayer, B.G., Hughes, D.W., Stark, R.E. \& Epand, R.M. (1999). Studies of phospholipid hydration by high-resolution magic-angle spinning nuclear magnetic resonance. Biophys. J., 76, 387-399, 0006-3495.

Zuhorn, I.S., Oberle,V., Wisser, W.H., Engberts, J.B.F.N., Bakowski, U., Polushkin, E. \& Hoekstra, D. (2002). Phase behaviour of cationic amphiphiles and their mixtures with helper lipids influences lipoplex shape, DNA traslocation and transfection efficiency. Biophys. J., 83, 2096-2108, 0006-3495.

Zuhorn, I.S., Visser, W.H., Bakowsky, U., Engberts, J.B. \& Hoekxtra, D. (2002). Interference of serum with lipoplex-cell intraction: modulation of intracellular processing. Biochim. Biophys. Acta, 1560, 25-36, 005-2736.

Zuhorn, I.S., Bakowski, U., Polushkin, E., Wisser, W.H., Stuart, M.C.A., Engberts, J.B.F.N. \& Hoekstra, D. (2005). Nonbilayer Phase of Lipoplex-Membrane mIxture Determines Endosomal Escape of Genetic Cargo and Transfection Efficiency. Mol. Ther., 11, 801810, 1525-0016. 


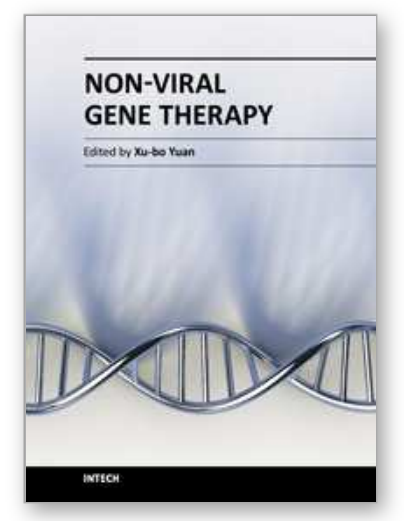

\author{
Non-Viral Gene Therapy \\ Edited by Prof. Xubo Yuan
}

ISBN 978-953-307-538-9

Hard cover, 696 pages

Publisher InTech

Published online 07, November, 2011

Published in print edition November, 2011

This book focuses on recent advancement of gene delivery systems research. With the multidisciplinary contribution in gene delivery, the book covers several aspects in the gene therapy development: various gene delivery systems, methods to enhance delivery, materials with modification and multifunction for the tumor or tissue targeting. This book will help molecular biologists gain a basic knowledge of gene delivery vehicles, while drug delivery scientist will better understand DNA, molecular biology, and DNA manipulation.

\title{
How to reference
}

In order to correctly reference this scholarly work, feel free to copy and paste the following:

Michela Pisani, Giovanna Mobbili and Paolo Bruni (2011). Neutral Liposomes and DNA Transfection, Non-Viral Gene Therapy, Prof. Xubo Yuan (Ed.), ISBN: 978-953-307-538-9, InTech, Available from: http://www.intechopen.com/books/non-viral-gene-therapy/neutral-liposomes-and-dna-transfection

\section{INTECH}

open science | open minds

\author{
InTech Europe \\ University Campus STeP Ri \\ Slavka Krautzeka 83/A \\ 51000 Rijeka, Croatia \\ Phone: +385 (51) 770447 \\ Fax: +385 (51) 686166 \\ www.intechopen.com
}

\author{
InTech China \\ Unit 405, Office Block, Hotel Equatorial Shanghai \\ No.65, Yan An Road (West), Shanghai, 200040, China \\ 中国上海市延安西路65号上海国际贵都大饭店办公楼 405 单元 \\ Phone: +86-21-62489820 \\ Fax: +86-21-62489821
}


(C) 2011 The Author(s). Licensee IntechOpen. This is an open access article distributed under the terms of the Creative Commons Attribution 3.0 License, which permits unrestricted use, distribution, and reproduction in any medium, provided the original work is properly cited. 